\title{
Verification of a coupled atmosphere-ocean model using satellite observations over the Adriatic Sea
}

\author{
V. Djurdjevic and B. Rajkovic \\ Institute of Meteorology, Faculty of Physics, Belgrade University, Belgrade, Serbia \\ Received: 24 July 2007 - Revised: 6 June 2008 - Accepted: 12 June 2008 - Published: 16 July 2008
}

\begin{abstract}
Verification of the EBU-POM regional atmosphere-ocean coupled model (RAOCM) was carried out using satellite observations of SST and surface winds over the Adriatic Sea. The atmospheric component has a horizontal resolution of 0.125 degree (approximately $10 \mathrm{~km}$ ) and 32 vertical levels, while the ocean component has a horizontal resolution of approximately $4 \mathrm{~km}$ with 21 sigma vertical levels.
\end{abstract}

Verification of the forecasted SST was performed for 15 forecasts during 2006, each of them seven days long. These forecasts coincide with the operating cycle of the Adriatic Regional Model (AREG), which provided the initial fields and boundary conditions for the ocean component of EBU-POM. Two sources of data were used for the initial and boundary conditions of the atmosphere: primary data were obtained from the European Center for Medium-Range Weather Forecasting (ECMWF), while data from National Centers for Environmental Prediction (NCEP) were used to test the sensitivity to boundary conditions.

Forecast skill was expressed in terms of BIAS and root mean square error (RMSE). During most the of verification period, the model had a negative BIAS of approximately $-0.3^{\circ}$, while RMSE varied between $1.1^{\circ}$ and $1.2^{\circ}$. Interestingly, these errors did not increase over time, which means that the forecast skill did not decline during the integrations.

The 10-m wind verification was conducted for one period of 17 days in February 2007, during a strong bora episode, for which satellite estimates of surface winds were available. During the same period, SST measurements were conducted twice a day, which enabled us to verify diurnal variations of SST simulated by the RAOCM model. Since ECMWF's deterministic forecasts do not cover such a long period, we decided to use the ECMWF analysis, i.e. we ran the model in hindcast mode. The winds simulated in this analysis were

Correspondence to: V. Djurdjevic

(vdj@ff.bg.ac.yu) weaker than the satellite estimates, with a mean BIAS of $-0.8 \mathrm{~m} / \mathrm{s}$.

Keywords. Meteorology and atmospheric dynamics (Mesoscale meteorology) - Oceanography: general (Ocean prediction) - Oceanography: physical (Air-sea interactions)

\section{Introduction}

Ocean forecasts are needed in areas such as transportation, exploitation of marine and bottom regions, environmental issues, and security issues. Compared with weather (atmospheric) forecasting, the forecasting of the oceans or seas is a relatively new idea. It has only recently become possible due to increased knowledge about the state of the oceans and seas. Previously, global and local climatological methods offered only relatively low resolution. Because of advances in what can be accurately measured using classical and modern devices, and because of the use of remote sensing and measurements of SST and sea surface elevation, we are able, at least in some world regions, to obtain a three-dimensional snapshot of ocean conditions accurate enough for forecasting purposes.

The two biggest challenges to forecasting are knowledge of the initial fields, as mentioned above, and reliable forcing data, which must be supplied from an atmospheric forecast model. In contrast to the relatively fast time scale of atmospheric change, time scales for ocean changes are much longer, so a short-range forecast of 7-10 days for the ocean is at the edge of reliability of atmospheric forecasts. In addition to their longer time scales, oceans, and in particular shallower seas, develop structures with much shorter spatial scales. Thus, we need relatively high-resolution atmospheric forcing.

The question of the Adriatic response to atmospheric forcing and its possible influence back onto the atmosphere has been the subject of numerous studies. Orlic et al. (1994)

Published by Copernicus Publications on behalf of the European Geosciences Union. 
analysed the Adriatic response to wind forcing by creating a modified bora and siroco climatology, and they were able to reproduce the general features of the sea. During bora winds, the response was quite complex, developing several lows and highs in agreement with the wind stress curl field. In the case of siroco, the currents produced were controlled by the bottom slope and wind stress curl. In some cases, siroco may cause the reversal of currents along the Adriatic western coast. Artegiani et al. (1997) defined the open ocean seasonal climatology of the basin based on a comprehensive historical hydrographic dataset for the overall Adriatic Sea basin. They also defined the regional climatological seasons by computing the average monthly values of heat fluxes and heat storage using a variety of atmospheric data sets. Using these data sets, they examined heat exchange and storage. Enger and Grisogono (1998), in an idealized 2D study of bora winds, evaluated the influence of higher or lower uniform ocean temperature on the bora wind, and the influence of the SST structure on its extension over the Adriatic. Beg Paklar et al. (2001) examined the response of the Adriatic shelf waters and the Po river plume to a bora wind episode using a combination of the Princeton Ocean Model (POM) and the NCAR Mesoscale Model (MM5). Using a bulk method, atmospheric forcing was calculated from the winds, air temperatures, and humidities obtained by MM5, with spatial resolution of $9 \mathrm{~km}$ and temporal resolution of $1 \mathrm{~h}$. They concluded that high horizontal resolution in the numerical experiments is important for resolving the variability of the bora wind field along the shore and to correctly simulate the narrow filament observed in AVHRR images. Zavatarelli et al. (2002) analysed two different forcings based on ECMWF products, and found that the circulation shows large seasonal variability, with a largely barotropic state during winter and a baroclinic structure during summer. They also found that amplitudes may be affected by the strength of the wind-forcing field.

In 2002 and 2003, intensive, multidisciplinary studies of the northern and central Adriatic were conducted (Lee et al., 2005; Pasaric et al., 2006; Pullen et al., 2007; Jeffries and Lee, 2007; Dorman et al., 2006; Peters et al., 2007). This research involved significant empirical and modelling studies. The DOLCEVITA program (The Dynamics of Localized Currents and Eddy Variability in the Adriatic) investigated the mesoscale and sub-mesoscale response to strong atmosphere and river forcing within the context of large-circulation studies. This projecthowed that with extremely high-resolution atmospheric forcing, including non-hydrostatic regimes, ocean models can form noticeable, albeit short-lived, surface current structures. In addition to DOLCEVITA, several other field programs were carried out in 2002-2003, such as the Mesoscale Alpine Program (MAP, 1999), the European Margin Strata Formation EUROSTRATAFORM), and the Adriatic Circulation, West Istria, and East Adriatic Coastal Experiments (ACE, WISE, EACE).
Pullen et al. (2003), in high-resolution studies of the Adriatic using the Navy Coastal Ocean Model (NCOM; 2-km resolution) forced by COAMPS (4- and 36-km resolution), were able to produce realistic fine-scale bora features with an enhanced-resolution atmospheric model. The superior atmospheric forecasts produced by the 4-km nested grid compared to the $36-\mathrm{km}$ nested grid also improved the ability of the ocean model to generate wind-forced currents when evaluated against Acoustic Doppler Current Profiler (ADCP) observations. Mantziafou and Lascaratos (2004) analysed general circulation and deep-water formation (DWF) processes in the Adriatic basin using climatological forcing using ECMWF Reanalysis data $\left(1^{\circ} \times 1^{\circ}\right)$ from $1979-1994$. The model reproduced the main basin features of the general circulation, as well as the water mass distributions and their seasonal variability. They showed that the DWF rates and their mass characteristics in a given year depend not only on the atmospheric conditions prevailing for that year, but on conditions prevailing during the previous year as well, thus leading to the concept of a "memory" of the basin. Signell et al. (2005) assessed the wind quality in oceanographic modelling by indirectly comparing simulated waves using the SWAN model to wave measurements at the ISMAR oceanographic tower in Venice. In that study, the authors analysed forcing in three different models of increasing horizontal resolution:. ECMWF; LAMBO, LAMI; and COAMPS. They were able to demonstrate that increased horizontal resolution increases the quality of the forcing.

Oddo et al. (2005) analysed and simulated the intra-annual variability of the Adriatic Sea circulation for 2000-2002. The forcing was based on 6-h ECMWF analyses, and the model predicted sea surface temperatures. The interactive surface momentum and heat fluxes were computed. The model had an open boundary at the southern end of the Adriatic, where it was connected to a Mediterranean general circulation model. Model results for the simulated years show a strong interannual variability of the basin-averaged proprieties and circulation patterns, linked to the atmospheric forcing variability and the Po river runoff. The years 2000 and 2002 were characterized by a weak surface cooling (with respect to climatological values) and well-marked spring and autumn river runoff maxima, while 2001 was characterized by stronger wind and heat forcing (autumn cooling) but no river runoff autumn peak, even though the total amount of water inflow during winter and spring remained the same. Beg Paklar et al. (2005) conducted several numerical experiments in which POM was forced with northeasterly winds and climatological variability along the shore. These experiments showed the influence of spatial variability in the bora wind field on the surface currents in the northern Adriatic. Orlic et al. (2006) looked at the response of the AdriaticMediterranean system during the anomalous winter season in 2002-2003. As a result of wintertime forcing, they were able to produce two different circulation systems, one within the Adriatic and the other between the Adriatic and east 
Mediterranean; these systems differed in both their spatial but and temporal scales.

Similarly to their work in 2003 (Pullen et al., 2003), Pullen et al. (2007) used the semi-coupled NCOM model and the coupled COAMPS model, both with relatively high resolution (2-4 km for the ocean and atmosphere, respectively) to investigate situations with both strong and weak winds. They assessed their results using remote and in situ measurements over water, as well as coastal wind observations. These studies also analysed coupled and semi-coupled configurations. They demonstrated that the coupled model performed better.

Several of these papers showed clearly that relatively highresolution atmospheric forcing is required to resolve or reproduce mesoscale features documented in extensive field investigations. In most of these studies, the modellers created fluxes from diagnostically computed, 2-m temperatures and $10-\mathrm{m}$ winds using the corresponding atmospheric model, various bulk models, or some other approach. Although slightly inconsistent, this approach does succeed in taking into account high-resolution features in the developed SST. This is important because ocean-atmosphere temperature gradients play a very important role in energy exchange.

In addition to atmospheric forcing, fresh water inflow plays an important role due to the relatively small size of the Adriatic. At present, global models are the main sources of forcing fields for periods of 5-10 days. They all include some degree of interaction with the ocean surface, either by being coupled to an ocean model of more or less complexity, or by specifying SST, usually through some type of climatology. Limited-area models are another possible source of atmospheric forcing, though these rely on the initial fields and boundary conditions of global models. Due to a general increase in the quality of these global and limited-area models, the number of operational or semi-operational ocean forecasts is rapidly increasing. A two-step approach that uses a global and then a limited-area model solves the problem of the need for high-resolution forcing. Similarly to the case of an atmospheric model, the Local Ocean model relies on a global (basin) scale model for initial and boundary conditions. Such forecasts are produced at several centres. For the Mediterranean Sea, the operational forecasting system MFSTEP (Pinardi et al., 2003) covers the whole basin and is run at INGV in Bologna. Using these forecasts as a starting point, regional or coastal models are run in several regions of the Mediterranean Sea. The regional or coastal models usually have higher spatial resolution. They are forced either with the same forcing used in the MFSTEP forecasts, or with different atmospheric forcing. This hierarchy of model domains solves or simplifies the problem of the boundary conditions, which is the third-biggest problem in ocean forecasting.

From October 2001 to November 2006, two large projects were devoted to beginning operational forecasts for the Adriatic Sea: the Adriatic Sea Integrated Coastal Areas and River Basin Management System Project (ADRI-
COSM), and its extension (ADRICOSM-EXT) (Zavatarelli and Pinardi, 2003; Manzella et al., 2003). This forecasting system, operating under the name AREG, has been run once a week since April 2003. The Institute of Meteorology at the Faculty of Physics of Belgrade University focused on producing the atmospheric forcing. For this purpose, a coupled, limited-area, atmospheric-ocean model was created with the aim of increasing the quality and length of the forecast. The atmospheric component is the Eta Belgrade University model (EBU), NCEP's operational model at the time, and the ocean component is the Princeton Ocean Model (POM).

Ocean simulations or forecasts can be verified in several ways. The most direct and most accurate way is through in situ measurements. Nevertheless, even where such measurements are available, their spatial coverage is usually limited, and therefore some kind of spatial interpolation must be used. The other two alternatives are remote sensing of SST or the indirect approach of coupling a wave model to an ocean model and verifying the results (Signell et al., 2005). The question of forcing, i.e., measuring the fluxes, is far more complicated. In principle, fluxes can be measured in situ, but due to their high spatial and temporal variation, we require even denser networks than for mean fields in order to represent them properly.

The other possibility is remote measurements of $10-\mathrm{m}$ winds and STT, which we compare with the 10-m winds and SST forecast by an atmospheric model. A limitation of this method is time sampling, since successive satellite passes occur only every 12 or $24 \mathrm{~h}$, and the spatial resolution is limited to approximately $25 \mathrm{~km}$. At present, in situ measurements remain superior to remote measurements, which also can be limited by precipitation or clouds in the area of interest. Nevertheless, remote sensing of ocean fields does present three important advantages over in situ measurements: (1) a much larger area can be covered in a way that is uniform both through time and space, and at a higher sampling frequency than in possible with other approaches; (2) the spatial resolution is much higher; and (3) they can easily be incorporated into an operational system. Within both ADRICOSM projects, the CNR-ISAC (Rome) sought to supply the project community with both SST and 10-m wind measurements. We have conducted our verification using those data.

\section{The model}

The model is a fully coupled atmosphere-ocean model with exchanges of fluxes and SST performed at every atmospheric physics time step, with atmospheric resolution of $0.125^{\circ}$, data exchange occurs every $90 \mathrm{~s}$. As noted above, the model's atmospheric component is EBU, a version of NCEP's Eta model, while the ocean component is POM (Djurdjevic and Rajkovic, 2002). This model is referred to subsequently as EBU-POM. The connection between the two components is through a novel coupler that performs the exchange of fluxes 


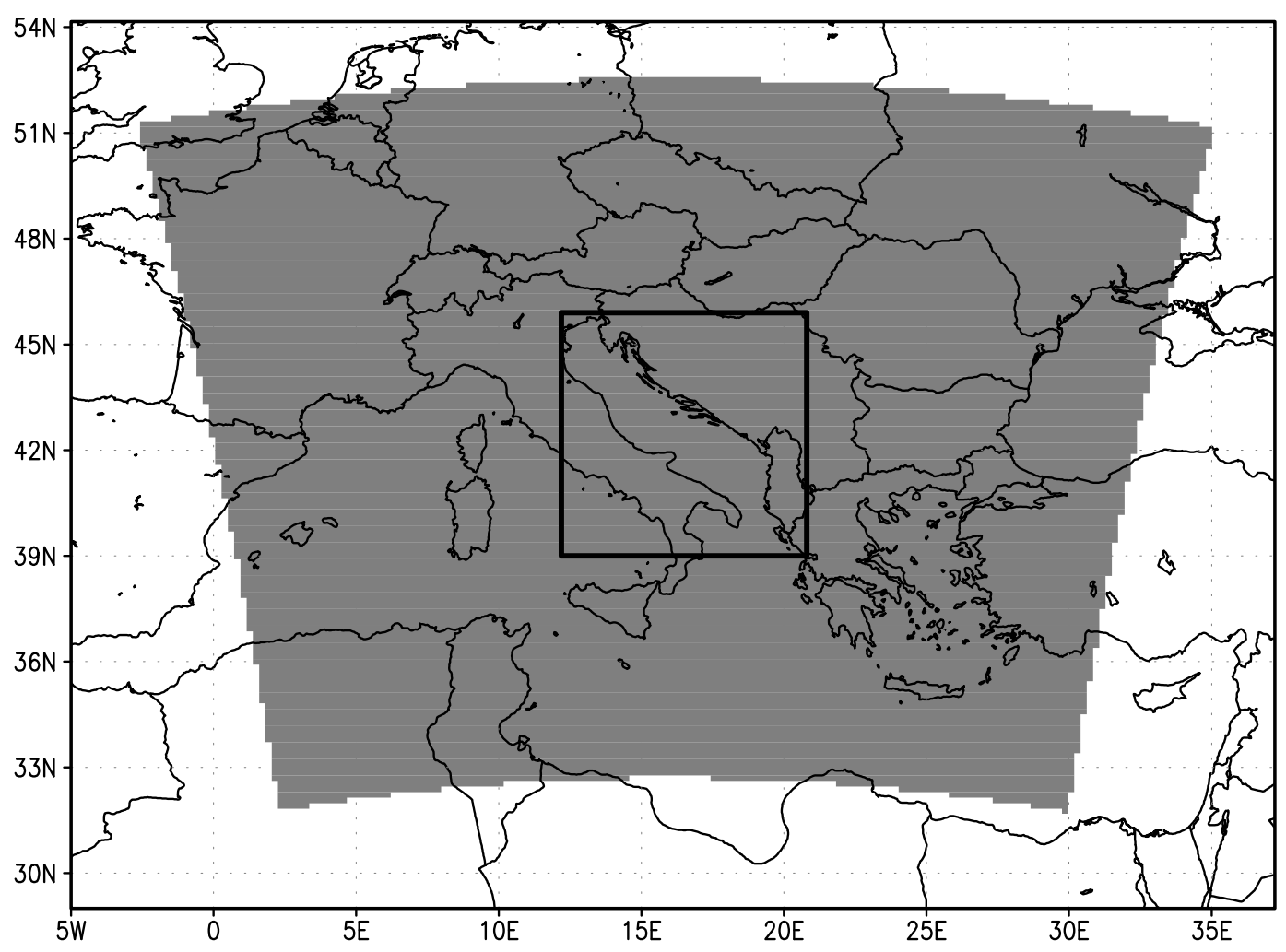

Fig. 1. Overlap of the atmosphere and ocean model domains. The atmosphere domain is in gray, while the ocean domain is the black rectangle at the centre of the picture.

and SST. Exchanged fluxes are calculated using the atmospheric component and used directly, without any additional parameterization.

\subsection{The atmospheric component}

The atmospheric component is a limited-area forecast model defined on the E-grid according to the nomenclature of Arakawa and Wininghoff (Winninghoff, 1968; Arakawa and Lamb, 1977) and with eta vertical coordinate (Mesinger et al., 1988). Its dynamic core has an efficient time-stepping, with a short time-step for the forward-backward gravity wave scheme modified so as to address the E-grid's lattice separation problem (Mesinger, 1974; Janjic, 1979), a longer time step for its conservative advection schemes (Janjic, 1984), and a still longer time step for the physics terms. The physics package consists of a surface scheme (Mahrt et al., 1988), a radiation scheme (Fels and Schwarzkopf, 1975), a turbulence closure sub-model (Mellor and Yamada, 1974; Mellor and Yamada, 1982; Janjic, 1990), a viscous sub-layer (Janjic, 1996) and a convection parameterization (Betts, 1986; Betts and Miller, 1986; Janjic, 1990). The centre of the atmospheric model is at $16^{\circ} \mathrm{E}, 42.5^{\circ} \mathrm{N}$ and the horizontal resolution is $0.125^{\circ}$. In the vertical direction, the model has 32 levels, with the first level at $20 \mathrm{~m}$ and the top at $10 \mathrm{mb}$.

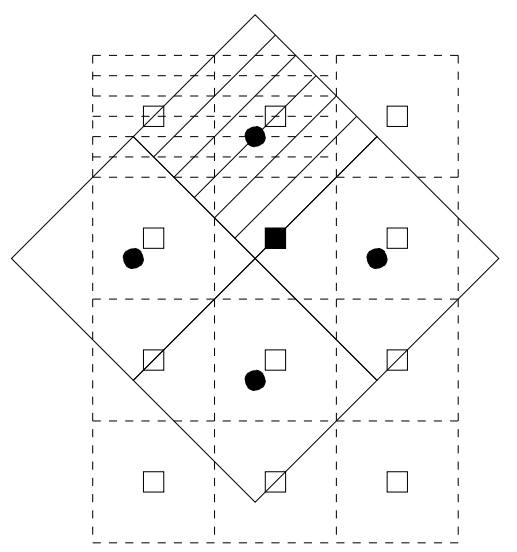

Fig. 2. Overlap of the land and sea masks. The diamond represents four grid points of the atmospheric model, denoted by the filled circles. The dashed rectangle represents twelve grid points of the ocean model, denoted with empty squares. The top grid point of the atmospheric model is a land point. The top and left points, indicated by dashed lines, are land points of the ocean model. The filled square is a water point for the ocean model, but a land point for the atmospheric model. 


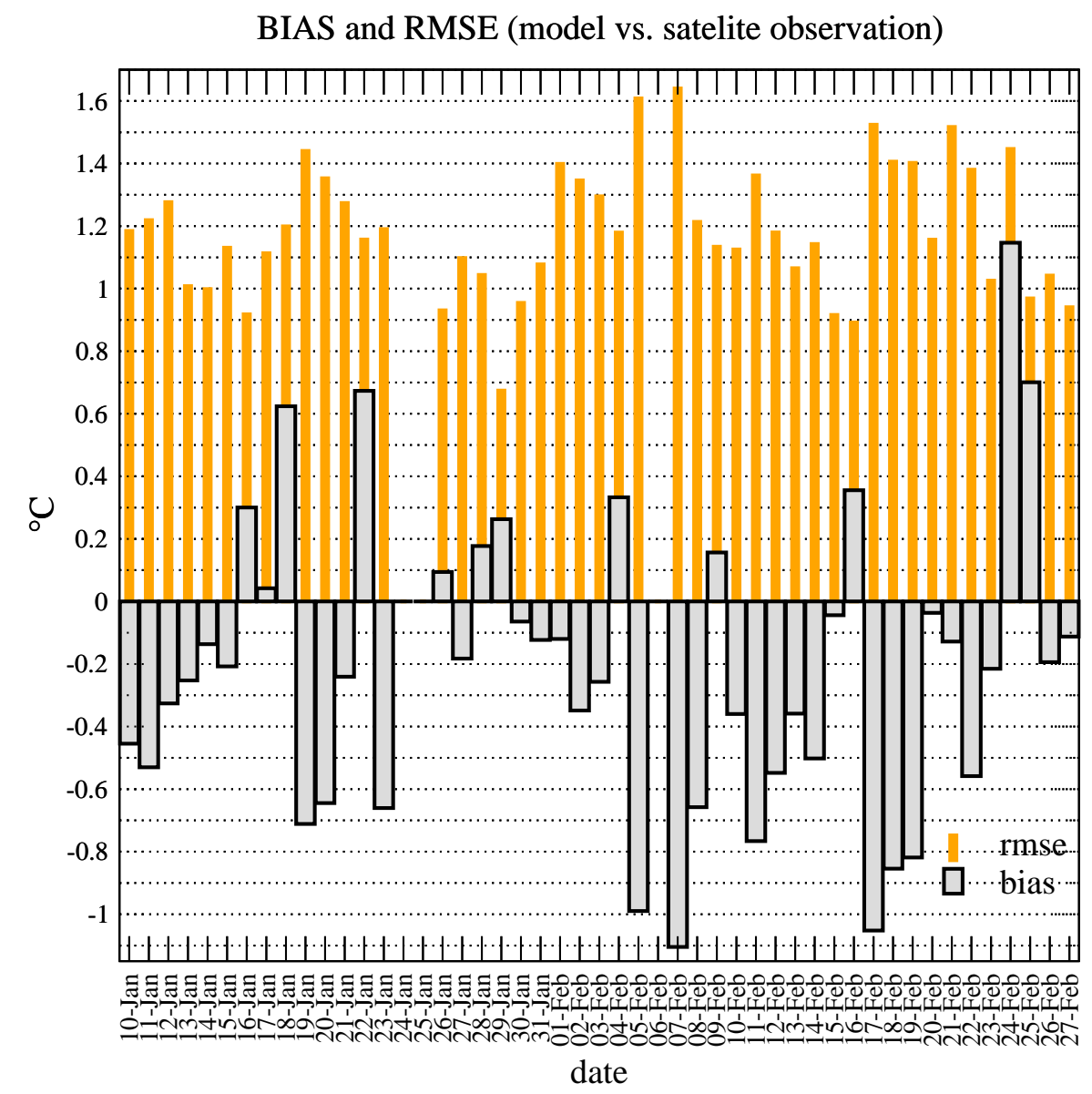

Fig. 3. Daily values of area-averaged BIAS and RMSE for the period of 10 January-27 February 2006.

\subsection{The ocean component}

POM is a three-dimensional, primitive equation, numerical model (Blumberg and Mellor, 1987; Mellor, 2002). Its horizontal grid uses curvilinear orthogonal coordinates on a $\mathrm{C}$ grid (Arakawa and Wininghoff nomenclature), and its vertical coordinate is a sigma coordinate. The model has efficient time differencing, which is explicit in horizontal and implicit in vertical. It has a free surface, complete thermodynamics, and, second-order turbulence closure. Advection schemes use the finite volume approach, which is particularly suitable when using curvilinear orthogonal coordinates. Figure 1 shows both atmospheric and oceanic domains. Since the ocean component was initialized using AREG fields, we adopted the same geometry as in AREG in order to avoid horizontal and vertical interpolation. The model's grid is a regular lat-lon grid covering the region $39.0-46.0^{\circ} \mathrm{N}, 12.0-$ $20.0^{\circ} \mathrm{E}$ with horizontal resolution of $4 \mathrm{~km}$ and with 21 vertical levels.

\subsection{The coupler}

Due to the very different geometries of the two model components, special care was taken in coupling them together. In Fig. 2 we present a schematic representation of the overlap of these two grids in the models. In addition to different positions of the corresponding points, there is also a difference in the horizontal resolution in the two sub-models. The atmospheric component has a resolution roughly four times coarser than the oceanic one. That led to different land-sea masks, since both the atmosphere and ocean "saw" different distributions of sea and land. Thus, the same point could be seen as a land point by the atmospheric component and as an ocean point by the ocean sub-model. As a result, because of large differences in heat and momentum fluxes over land and sea, the energy and momentum exchange between the sea and the atmosphere would be wrong.

To avoid those errors, the ocean points are separated into two groups. The first group consists of the points that both the atmosphere and the ocean sub-models see as ocean points. The second group is the ocean points that are seen as land points by the atmosphere component. Fluxes at these 


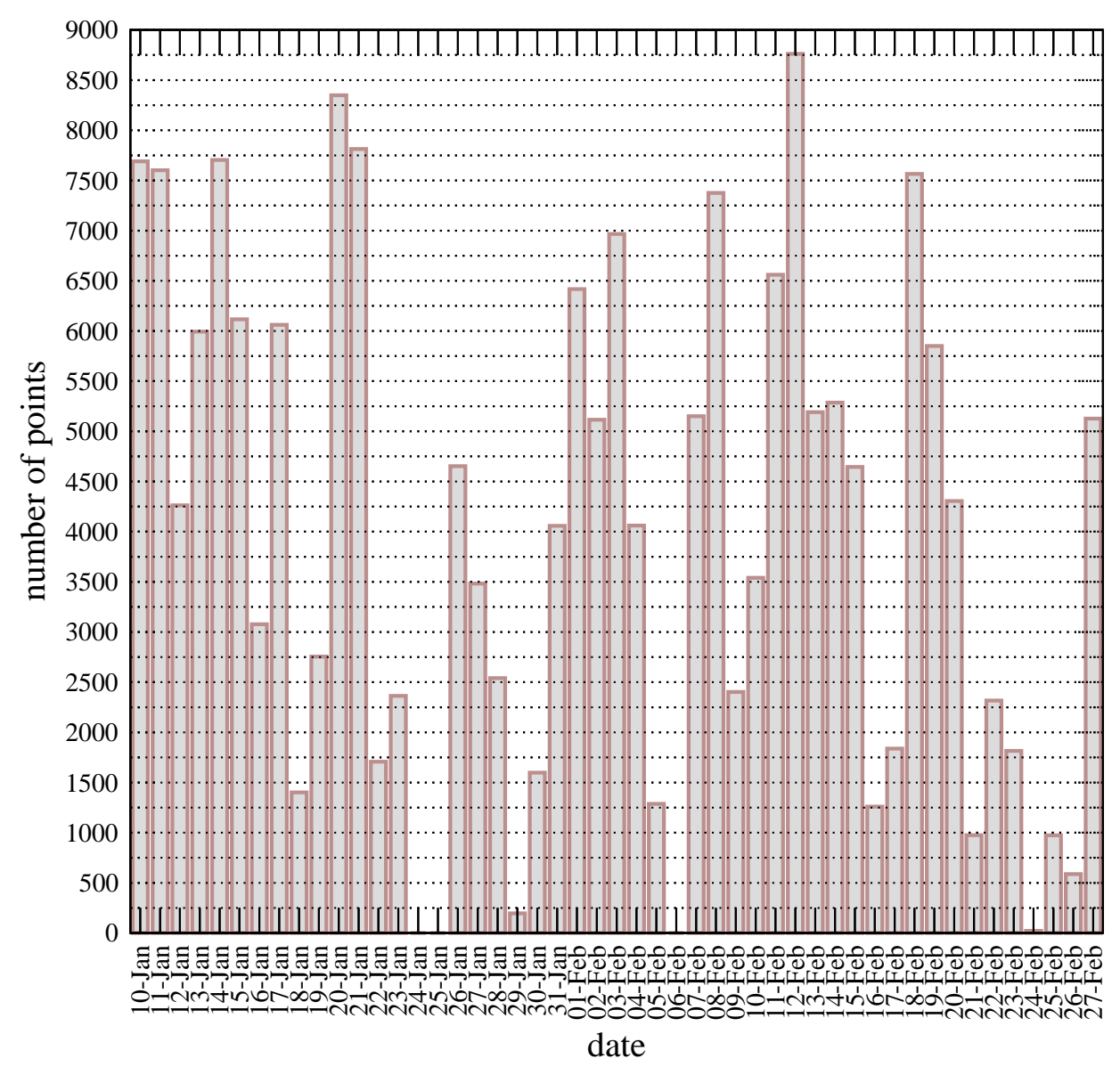

Fig. 4. Number of model grid points with satellite observations availabe.

points are computed in the following way: first, we compute average flux, with averaging carried out for all points in the first group. This serves as the first guess value. This value is improved by applying a Laplacian operator over the points belonging only to the second group. Fluxes for the first group are not changed by this procedure. As previously noted, the exchange of fluxes and SST is conducted every time that physics is done in the atmospheric model. At the end of this step, the surface fluxes are diagnosed and taken by the "coupler". The fluxes in question are the following: the momentum flux; two heat fluxes, latent and sensible; and two radiative fluxes, short- and long-wave. The latent heat flux is the sink for fresh water. The coupler interpolates values horizontally onto the ocean grid. Interpolated fluxes force the ocean over several ocean time steps with total length equal to the atmospheric physics time step. The ocean surface then has an updated temperature that is read by the "coupler". Formation of SST on the atmospheric grid is done by averaging over four ocean points that correspond to one atmospheric point, except near coasts where three or even two points may be used.

\subsection{The model setup}

Both forecast and hindcast experiments were conducted. In the prognostic mode, the initial fields were computed starting with the analysis, while the boundary conditions were computed from the forecasts of the ECMWF and NCEP. The length of integration was seven days, as in the case of the AREG operational cycle. In the hindcast mode, we performed one run of 17 days in which both the initial fields and the boundary conditions were computed from the ECMWF analysis. The main source of data for our integrations was ECMWF. The NCEP runs were only used in sensitivity tests on boundary conditiuons. In both cases, analyses were horizontally interpolated to the E-grid and vertically interpolated according to the vertical grid distribution of the atmospheric component. The boundary conditions were extracted from the six-hour forecasts for the next seven days, after being horizontally and vertically interpolated onto the atmospheric grid. Initialization of the ocean component was a straightforward copy of the operational model data in the AREG/INGV setup. 

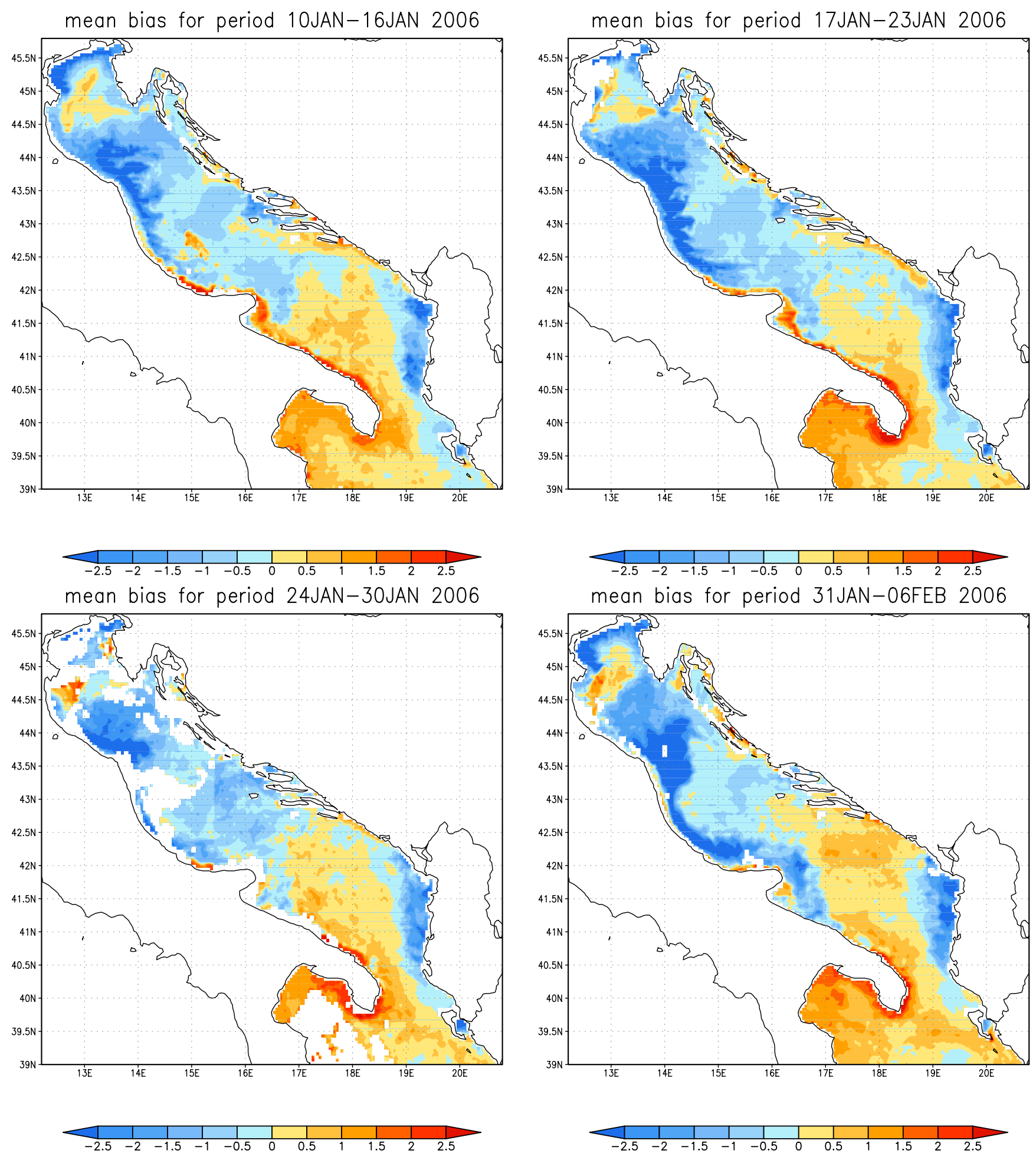

Fig. 5. Mean SST BIAS over the Adriatic area for four periods of seven days each: 10-16, 17-23, 24-30 January, and 31 January-6 February.

\section{Remote sensing of SST and surface winds}

Satellite oceanography is important for operational applications because satellite-based sensors can collect oceano- graphic data from large areas in a very short time. In the framework of the ADRICOSM and ADRICOSM-EXT projects, the Satellite Oceanography Group (GOS, Rome) developed a Fast Delivery System (FDS) for providing the 

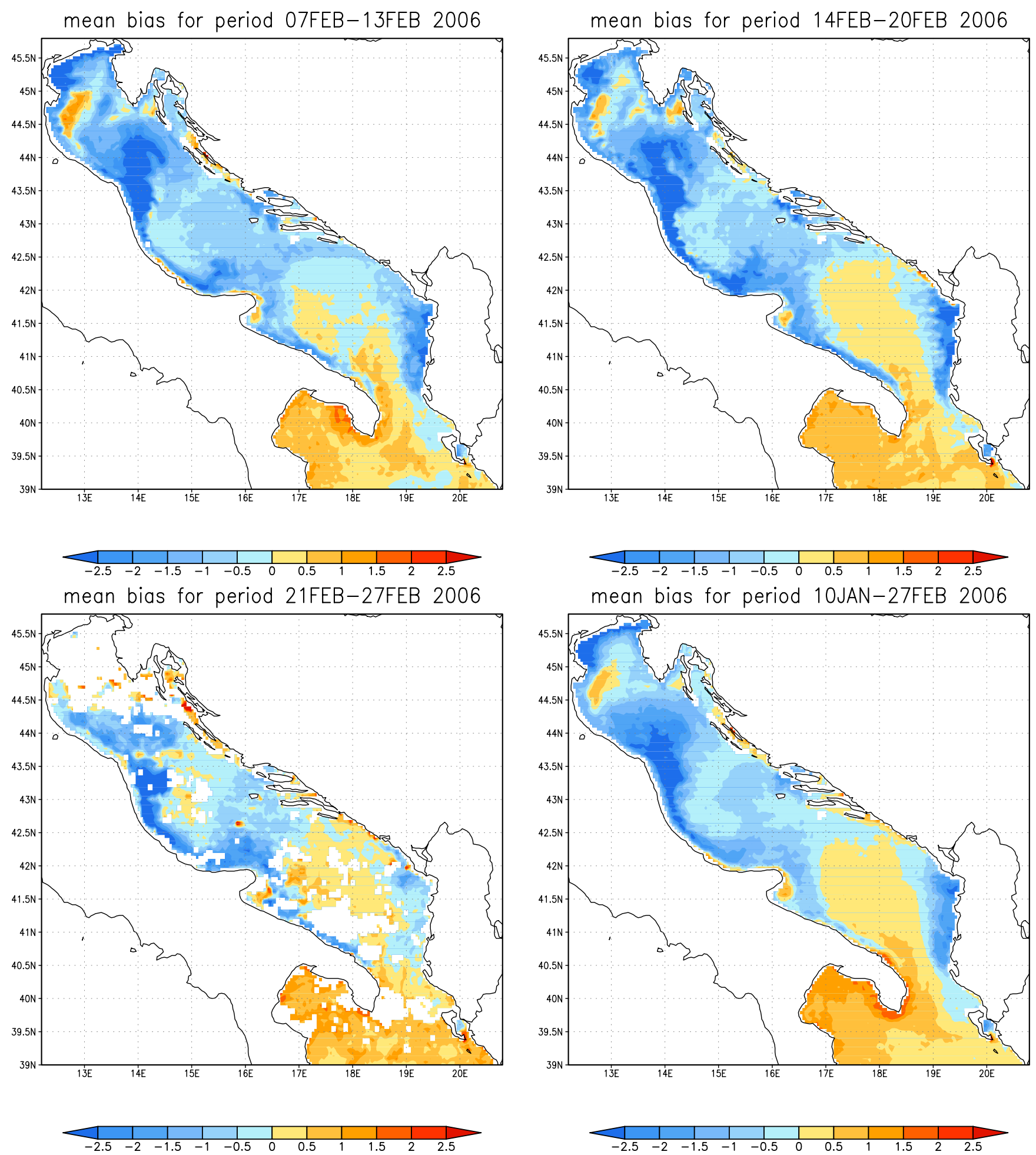

Fig. 6. Mean SST BIAS for three, seven-day periods 7-13, 14-20, 21-27 February and the entire period of 10 January-27 February over the Adriatic area.

partner modelling centres with remotely sensed ocean colour, sea surface temperature (SST) and, for a selected period, surface wind. Data are processed, mapped, and binned for the Adriatic Sea area in order to be assimilated into both ecosystem models and circulation models for the purpose of ocean forecasting. Further technological improvements 

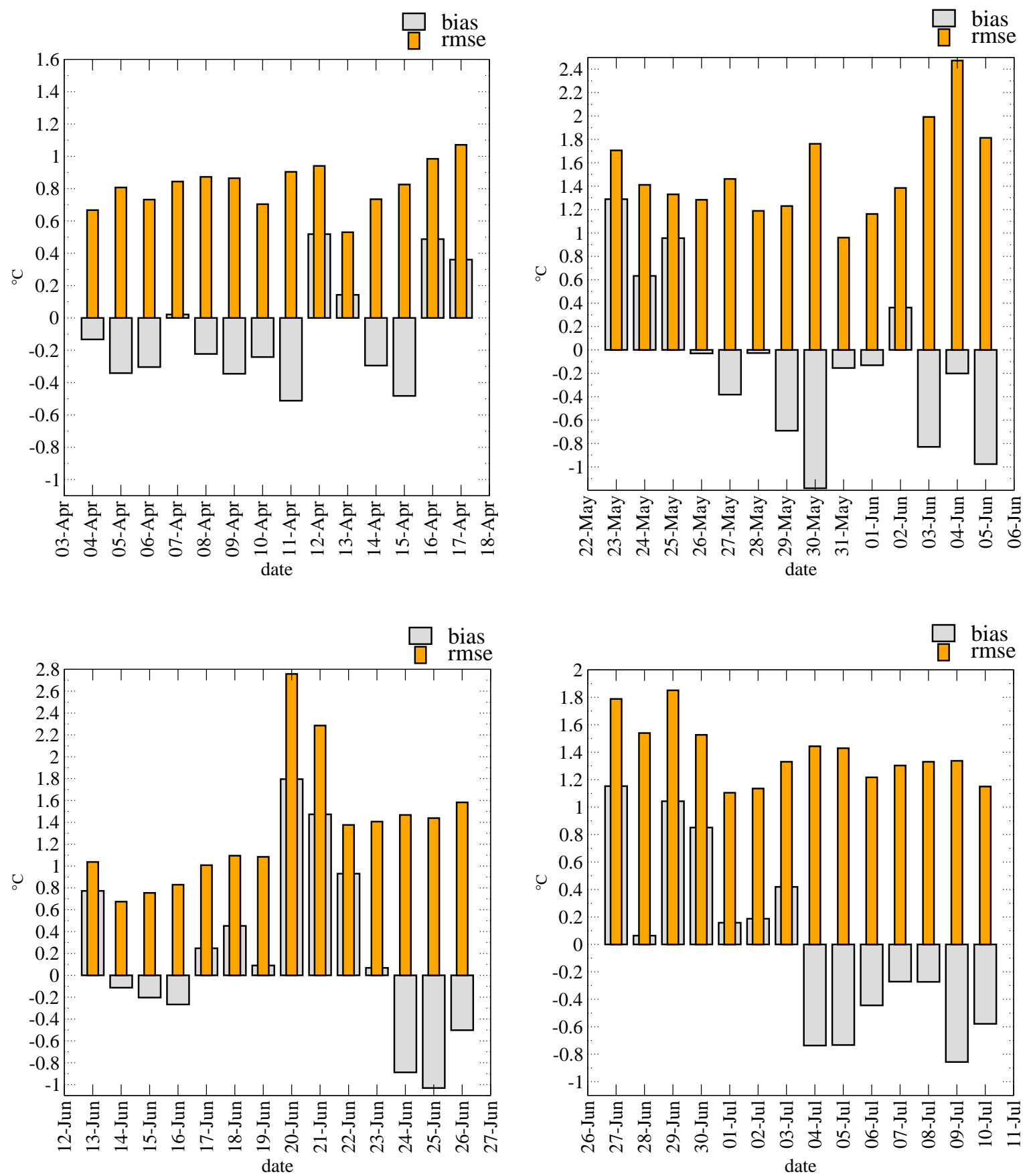

Fig. 7. BIAS and RMSE scores for eight forecasting periods, 3-18 April, 22 May-6 June, 12-26 June and 27 June-11 July, grouped in sets of two.

have permitted the building and optimization of a system suitable for meeting the increasing demand for near-real-time ocean colour and SST. Real-time images of SeaWiFS chlorophyll concentration, clouds/case I/case II, water flags, and true colour images, are obtained by processing the satellite passes using ancillary climatological data. These images are provided daily through an ad hoc automatic system that processes the raw satellite data and makes them available on the
Web within an hour of satellite acquisition. NOAA/AVHRR data are also acquired by the GOS ground station in Rome and managed by the FDS from the reception stage through to distribution. Daily SST maps of the Adriatic Sea are binned over the AREG model grid at $1 / 16^{\circ}$ resolution. Derivation of the SST fields involves three major steps: geophysical conversion, remapping, and declouding. 


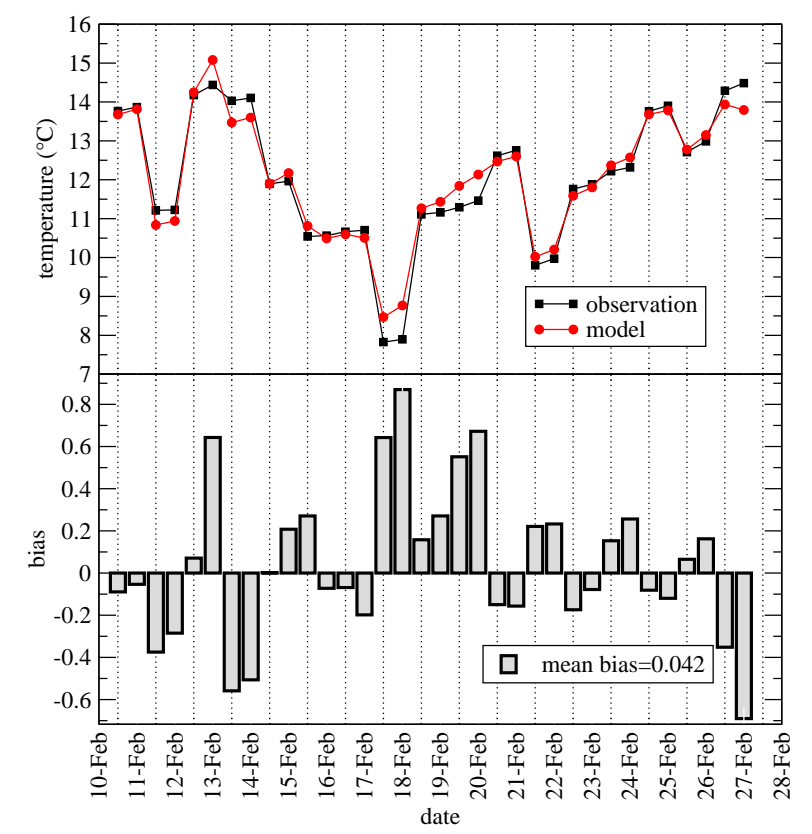

Fig. 8. Time series of diurnal variations of averaged SST (upper panel) and BIAS (lower panel) between model (red) and observations (black). Note that the observation areas are different for each date. This is a result of changes in satellite coverage from day to night. See the next figure for explanation.

Geophysical conversion is the transformation from sensor counts to single-channel radiance and multi-channel derived SST. The Pathfinder algorithm (Walton et al., 1998; Kilpatrick et al., 2001) has been identified as the algorithm providing the most accurate SST's based on comparison with independent observations (within $0.2^{\circ} \mathrm{C}$ ). Moreover, it was tested on observations from the Mediterranean Sea independent of the observations used to develop the algorithm, and it gave results equivalent to those of the global data set (D’Ortenzio and Marullo, 20000).

Remapping is the specification and application of a particular projection on which the image can be mapped. The specified mathematical transform is applied to a navigated image consisting of scaled geophysical data. Remapped data are specified only by the projection, the latitudinal and longitudinal centre of the image, and the output pixel size. The projection applied to the images is equi-rectangular, and it is the same projection as implemented in SeaWiFS to superimpose different products. The dimensions of the remapped images in the Adriatic Sea are $512 \times 600$, ranging from latitude $39.0-46.0 \mathrm{~N}$ and longitude $12.0-20.0 \mathrm{E}$.

Declouding is the identification of cloud-contaminated pixels in SST imagery. The Pathfinder SST procedures construct quality control fields based on spatial uniformity tests and deviations from the Optimally Interpolated REYNOLDS fields $\left(1^{\circ}\right.$ resolution, weekly average global SST), published weekly by NOAA. Low-quality pixels are defined as cloud- contaminated. However, this automated declouding procedure can erroneously identify clouds in areas of strong oceanic cloud fronts due to the coarse resolution of the REYNOLDS fields. Improvements to the declouding procedure are needed in the Adriatic Sea, where coastal fronts are strong. For more details, see Sciara et al. (2006).

\section{Results}

\subsection{Verification of SST}

All forecasts cover the period of 10 January to 17 July 2006. Results are presented in terms of BIAS and RMSE scores for the area-averaged SST (see Appendix for definitions). In Fig. 3, we present the verification of SST from 10 January to 27 February. It is important to note that although the figure shows results in a continuous fashion, the results comprise seven consecutive forecasts. The gap around 27 January is because satellite measurements were unavailable for that period. Figure 4 shows the frequency of the satellite observations during the same period. The mean value of RMSE was between $1.1^{\circ}$ and $1.2^{\circ}$, while BIAS was between $1.2^{\circ}$ and $-1.1^{\circ}$, with negative values during most of the period. The mean BIAS was approximately $-0.3^{\circ}$, which is very close to the observational error of $0.2^{\circ}$.

Importantly, the RMSE within each of the forecasts does not increase with time. In many cases, the error is largest at the beginning of the forecast period and it decreases as time goes on. Comparing each forecast score with number of grid points for which satellite observations were available, (19 January; 5, 7, 17, 21, and 24 February) shows that all large BIAS/RMSE values occur when the number of observations is small. A more complete picture of the differences between model and satellite SST is presented in Figs. 5 and 6 , where we show horizontal variations of SST BIAS over the Adriatic area for periods of 10 January-6 February and 7-27 February, respectively. We can see that over most of the area, BIAS is small (see light blue and light yellow colours). Near the coast, BIAS has larger absolute values and occurs nearly equally as negative and positive numbers. This phenomenon is a well-known problem when verifying SST from satellites in coastal areas with shallow waters. The last panel shows the mean BIAS for the entire seven-week period, from which we can conclude that BIAS exhibits the same behaviour. In Fig. 7, we present the BIAS and RMSE for the remaining forecasts. Scores exhibit similar behaviour, except for a single forecast from 20 to 27 June, when RMSE starts with a value of $2.7^{\circ}$. Even in that case, however, the RMSE decreases towards the end of the forecast.

\subsection{Sensitivity to the initial and boundary conditions}

All our forecasts were carried out using ECMWF predictions for both initial and boundary conditions. Another possible source for the initial or boundary conditions is NCEP. To 

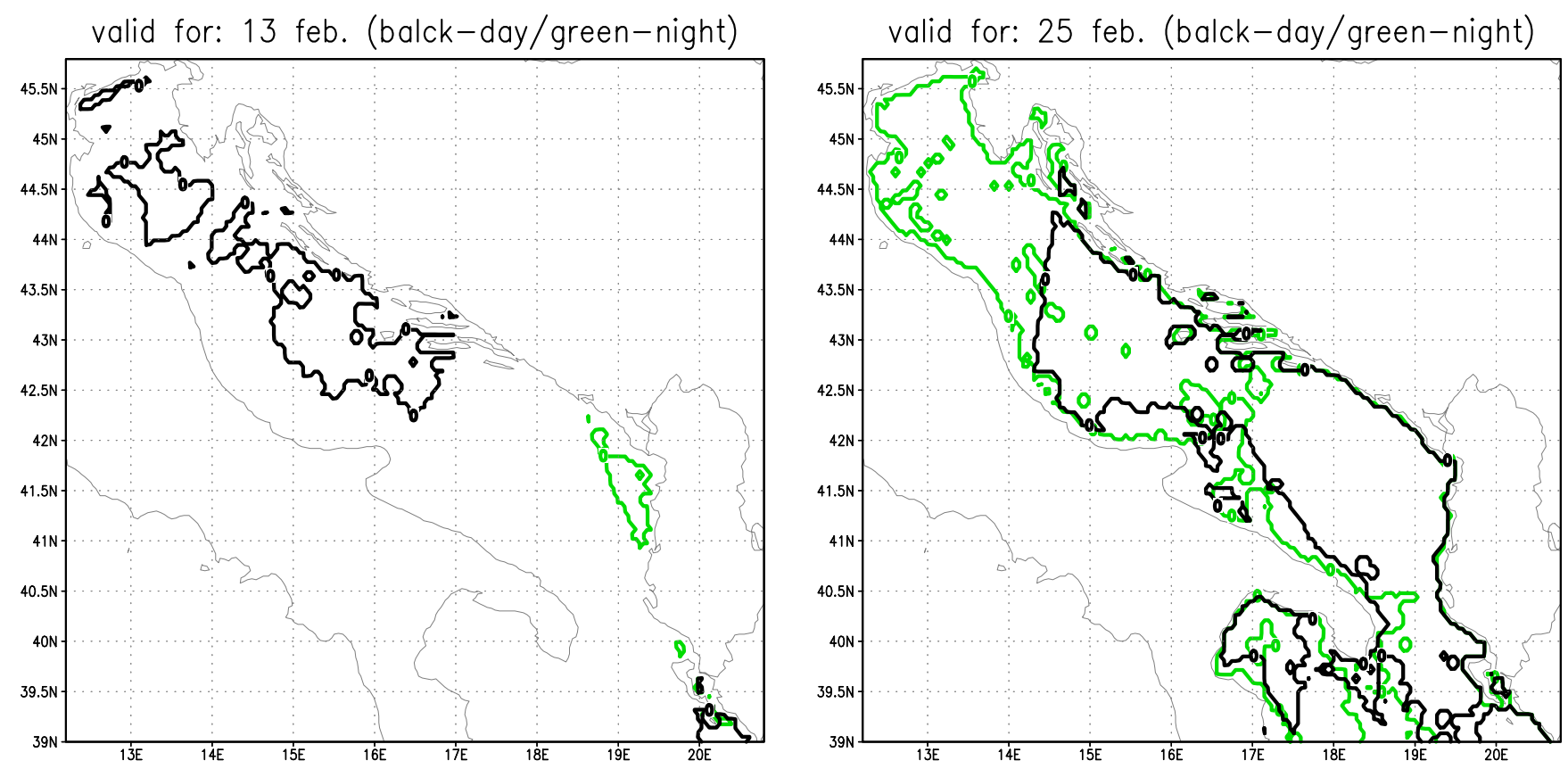

Fig. 9. The left panel shows an example of very small overlaps in satellite coverage from day to night. The data come from 13 February 2006. The green line denotes the night satellite pass, while the black line denotes the day satellite pass. Note that the two areas overlap only at the south entrance of the Adriatic and only very close to the Albanian coast. The right panel shows satellite coverage for 25 February. Note that in this case, the day and night coverage overlaps over an extensive portion of the Adriatic Sea.

check how the choice of data set can affect the resulting forecasts, we performed the same forecasts with the same model set-up but using NCEP fields. Nearly all NCEP-derived forecasts were quite close to the ECMWF-derived forecasts, except for the one shown in Fig. 10. The top panel shows BIAS for the 26 June forecast, showing the closeness between the two forecasts for the first four days. After the fourth day, the ECMWF-derived forecast deteriorates, while the BIAS for the NCEP-based forecast remains small. The middle panel shows the variation in SST over time, with the SST averaged over the entire Adriatic region in both forecasts. The ECMWF-based forecast is in red, the NCEP-based forecast is in black, and observations are in green. As with the BIAS score, we see that the two forecasts agree well for the first four days, after which the ECMWF-based one begins to deviate from the observations. Note that the SST was averaged over the whole Adriatic, whereas the observation area was smaller. Based on an examination of synoptic charts, the reason for this difference was that the ECMWF forecast did not capture the intensity and position of the front that was crossing the Adriatic during the period under study. Finally, the bottom panel shows a typical case where the two forecasts differ only slightly.

\subsection{Verification of the diurnal variation in SST}

Verification of the diurnal variation of SST is possible using data from two successive satellite passes. Results from the period from 10-27 February are presented in Fig. 8, with area-averaged SST shown in the upper panel and BIAS scores in the lower panel. The fields are for midnight and noon, local time, for a particular date; observations are marked with squares and forecasts are marked with circles. Dotted lines indicate midnight for each day. It should be noted that large variations in averaged SST, from one pair to another, are a result of differences in the size and position of verification areas, which depended on the cloud-free area. Possible differences in the area coverage are shown in Fig. 9, with the two panels corresponding to two different days, 13 and 25 February. The green line is the border of the coverage during the night, and the black line is the border of the coverage during the day. Therefore, for 13 February, the area covered by both night and day passes is very small and very close to the shoreline, while for 25 February, joint coverage was quite large. The corresponding differences between observed and forecasted SST are large for the first date and very small for the second one.

Scores are summarized in Table 1, which shows mean BIAS and RMSE values for night and day. Both scores are very similar for both daily satellites recordings of SST. Interestingly, BIAS (0.3) is much smaller than for the previous forecast runs, likely because boundary conditions are now extracted from the analysis instead of from the forecasts. The same is true for the RMSE $\left(\sim 1.2^{\circ}\right)$. 


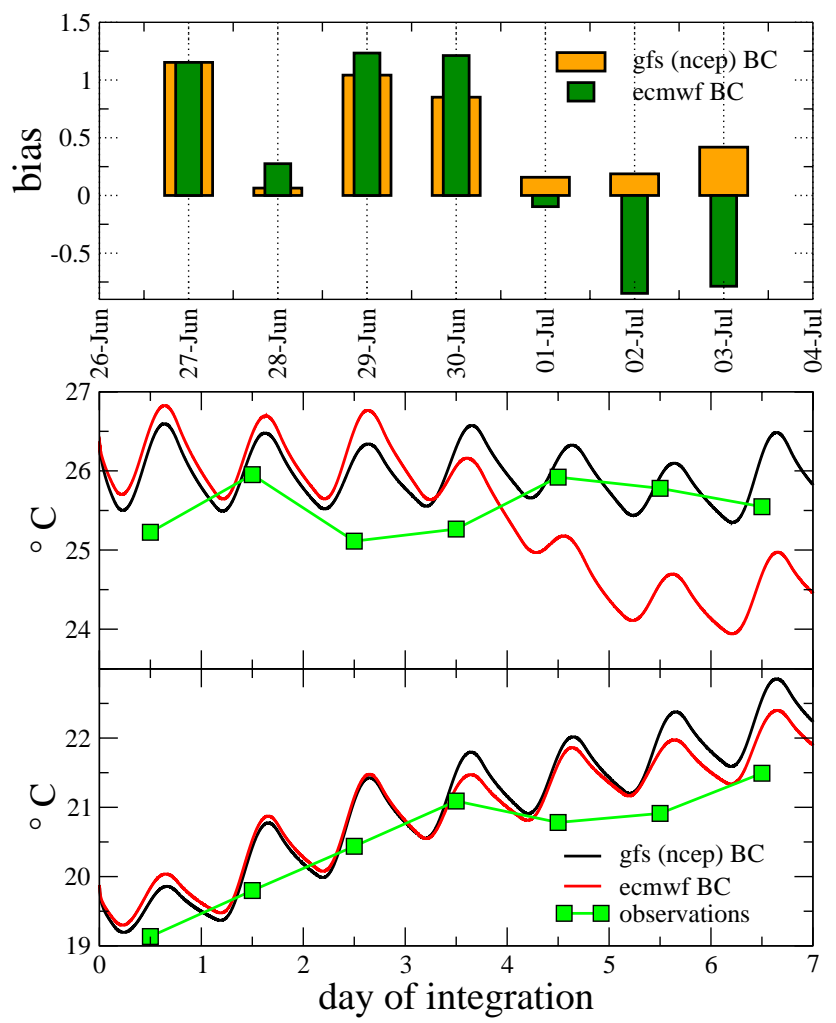

Fig. 10. The top panel shows BIAS scores for two different initial and boundary conditions. NCEP data are shown in orange, ECMWF data are shown in green. The period of integration was 26 June-4 July, 2006. The middle panel shows time series of areaaveraged SST over the whole Adriatic from both forecasts for the same period as in the previous figure; ECMWF is shown in red, NCEP in black, and observations in green. The bottom panel shows a time series of area-averaged SST for the forecast starting on 13 June 2006. Note that here the two forecasts are very close and both are close to the observed SST.

\subsection{Verification of $10-\mathrm{m}$ winds}

In the short-term forecasts, wind forcing dominates over buoyancy forcing, so $10-\mathrm{m}$ wind scores should be examined in more detail than the SST, which we assume to result primarily from buoyancy forcing. Actually, these two fluxes are interconnected "both" ways. Friction velocity, which is calculated from the surface winds, enters into the calculation of buoyancy fluxes. But that calculation, which involves parameterizations, depends on the local stability, which itself depends on the local buoyancy flux exchanges. The important difference between the wind and temperature fields is that the wind field has generally higher temporal and spatial variability, which can result in high variability of the friction velocity and therefore in all fluxes. This is particularly true for stronger winds, with an average above several meters per second (Djurdjevic and Rajkovic, 2002).
Table 1. Values for night and day mean scores for the 17-day hindcast.

\begin{tabular}{lcc}
\hline Time of day & BIAS & RMSE \\
\hline Night & 0.07 & 0.3 \\
Day & 0.02 & 0.4 \\
\hline
\end{tabular}

Wind verifications were performed using the satellitebased QuikSCAT scatterometer. QuikScat provides scientists and weather forecasters with data on ocean winds at $25-\mathrm{km}$ resolution and a typical accuracy of $1 \mathrm{~m} / \mathrm{s}$ in speed and $15^{\circ}$ in direction. As a part of the ADRICOM-EXT project, CNRISAC specially prepared $10-\mathrm{m}$ winds for a period of 17 days, from 11-27 February 2003. That period was characterized by the presence of the bora wind, which plays an important forcing role in the Adriatic. Near the end of the bora episode, the wind turned into Sirocco, the other prevailing wind of the Adriatic. Bora is a dry, cold wind that blows offshore over the Dinaric Alps, the mountain range along the eastern Adriatic coast. The bora's main characteristics are gust and intensity. Local intensification occurs as a result of channelling through the gaps in the mountain ranges, four of them being most prominent. The best-known area by the most intensive Bora is near Senj, the so-called Senj Jet. Another area known for such downhill wind is around Trieste, the Trieste Jet, though it spreads across the entire northern Adriatic. It is mostly a winter phenomena whose main season extends from December to March. Sometimes it occurs during summer, but only locally and for only a few days. The winter episodes are much longer and can last up to two or even three weeks.

The other wind that characterizes air circulation over the Adriatic is Siroko. It is spread along the entire length of the Adriatic coast and comes from the ESE, SE, or SSE directions. Siroko is the characteristic wind of the spring and fall seasons. Siroko occurs only rarely in the summer. We took advantege that Bora blew for a while and performed an extended forecast covering the whole period. The forecasts and observations are shown in Figs. 11-15, with observed wind vectors in black, flagged wind observations in red, and forecast winds in lighter colors.

For several days during the period of 16-27 February, we show surface winds at 06:00 and 18:00 local time. Before discussing the evolution of the wind field during the forecast period, some remarks about satellite-based wind measurements are necessary. Satellite measurement of the wind (both speed and direction) is very sensitive to the presence of clouds and precipitation. We did not have independent verification of these parameters, so instead we analysed the model's forecast of precipitation denoted by the gray isolines. Of course, the real clouds/rain may not coincide with the forecast ones, but the forecasts may nevertheless give some indication of the possible presence and position of 
valid for: 11 feb. $06 \mathrm{~h}$
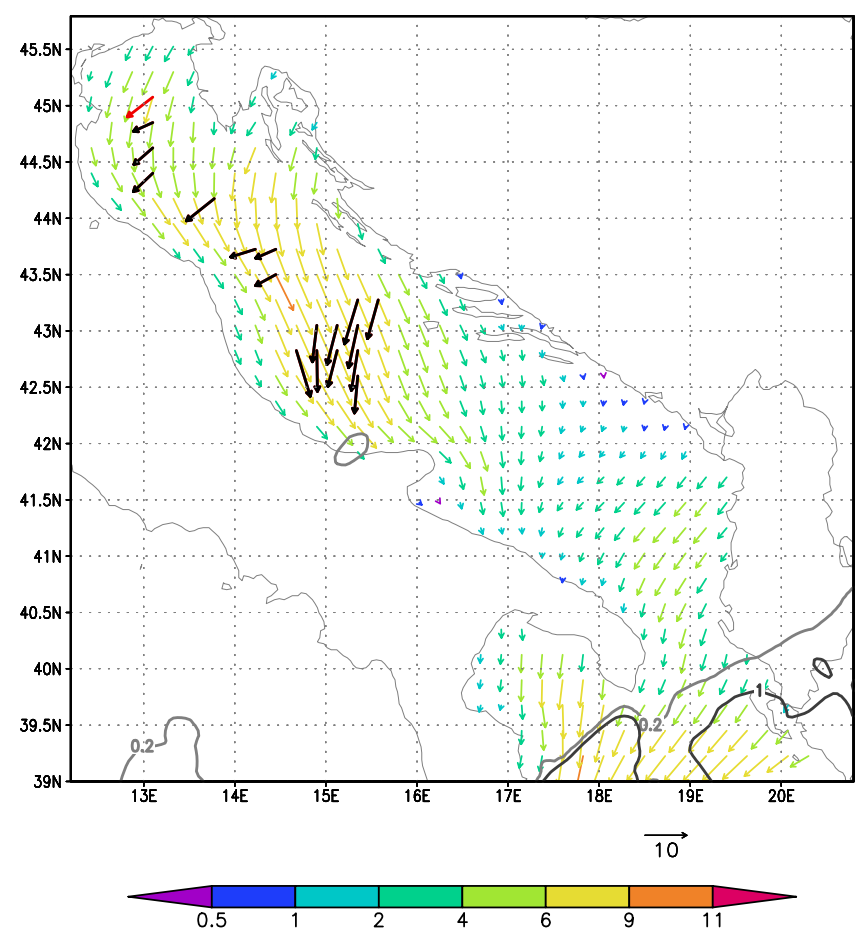

valid for: 12 feb. $06 \mathrm{~h}$
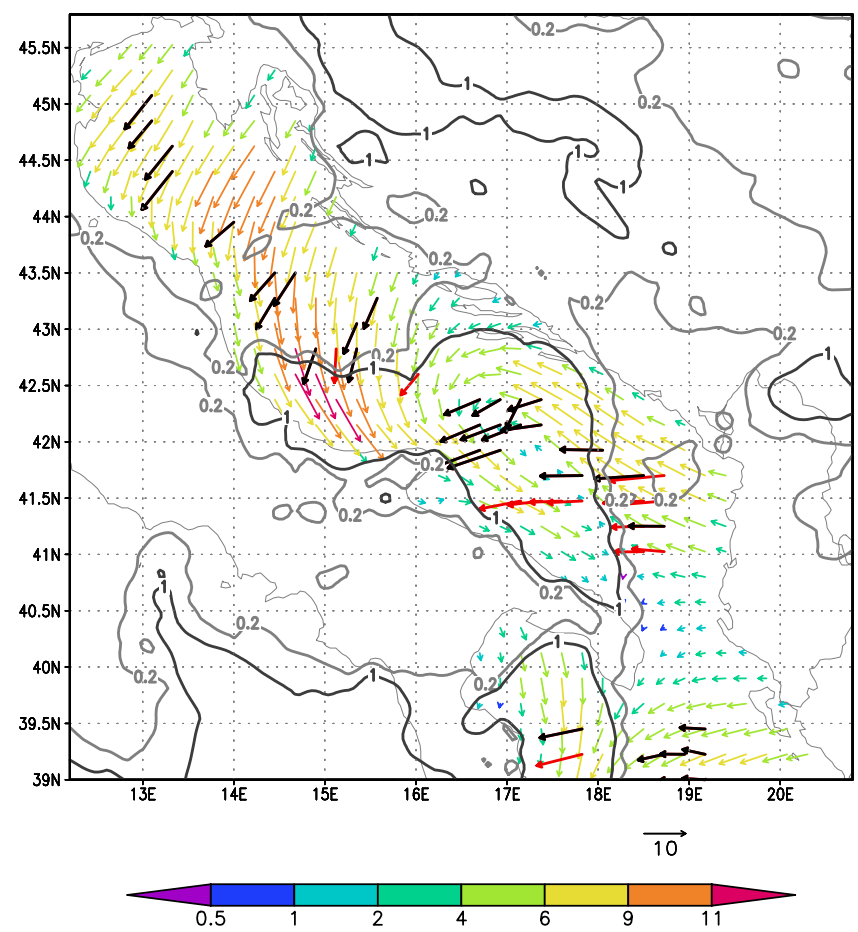

valid for: 11 feb. $18 \mathrm{~h}$
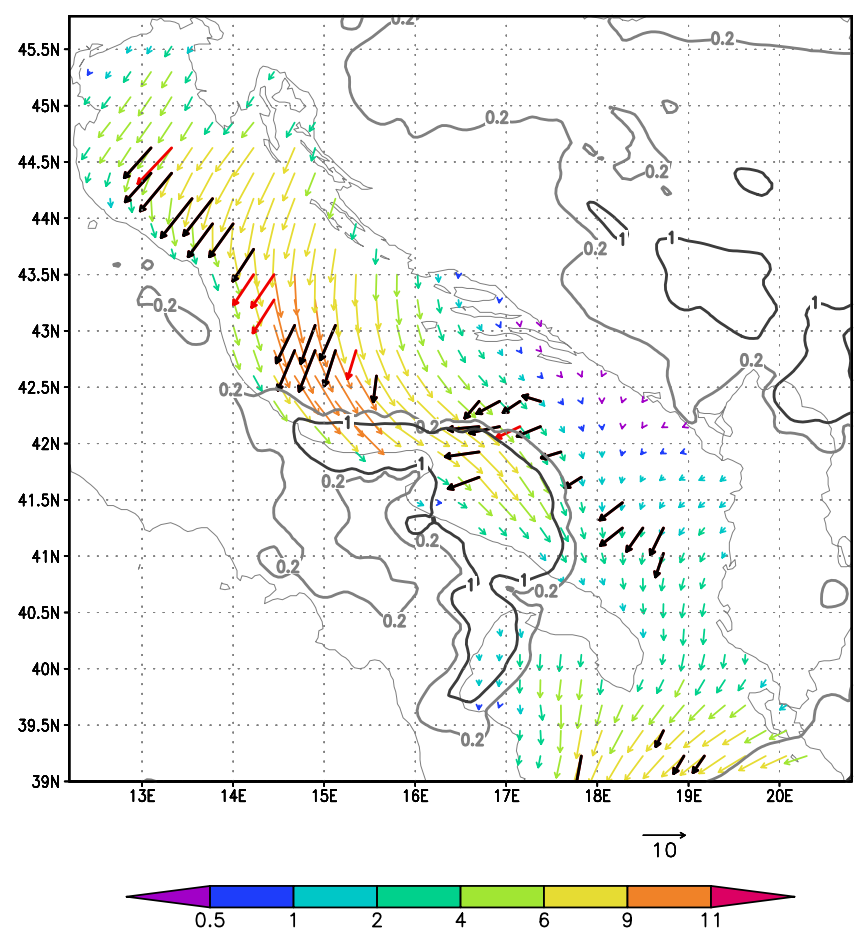

valid for: 12 feb. $18 \mathrm{~h}$
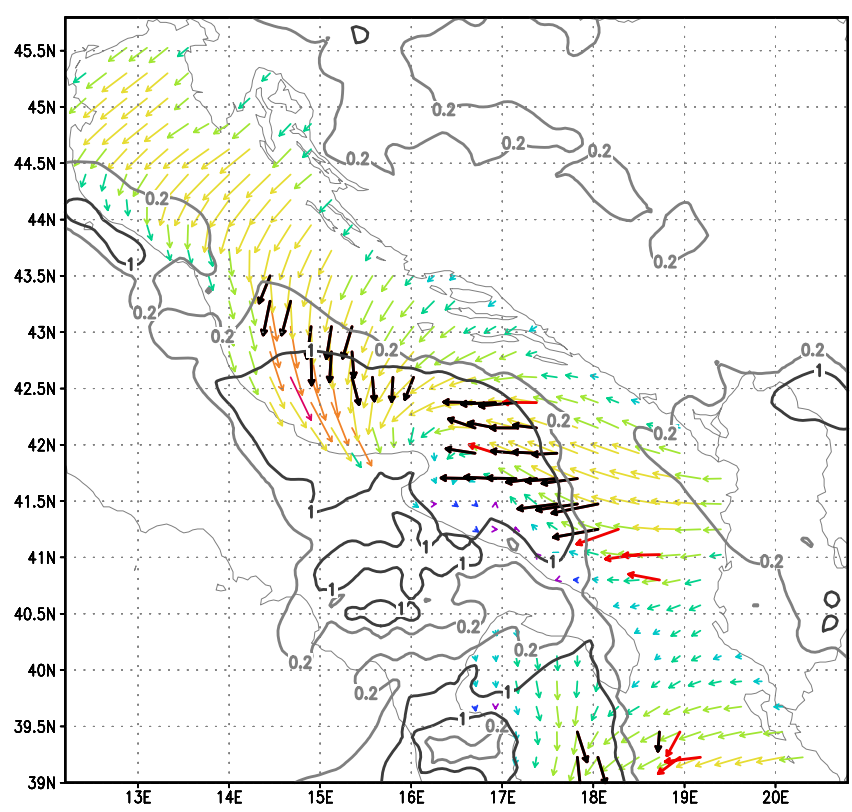

$\overrightarrow{10}$

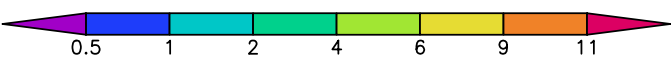

Fig. 11. Verification of the surface winds from satellite data. Forecasts are for 11-12 February for two satellite passes, at 06:00 h and 18:00 h. Heavy black arrows are observations, with flagged data indicated by red arrows. Forecast winds are shown in lighter colours. Gray indicates isolines of precipitation predicted by the model; these may indicate areas with rain or clouds. 


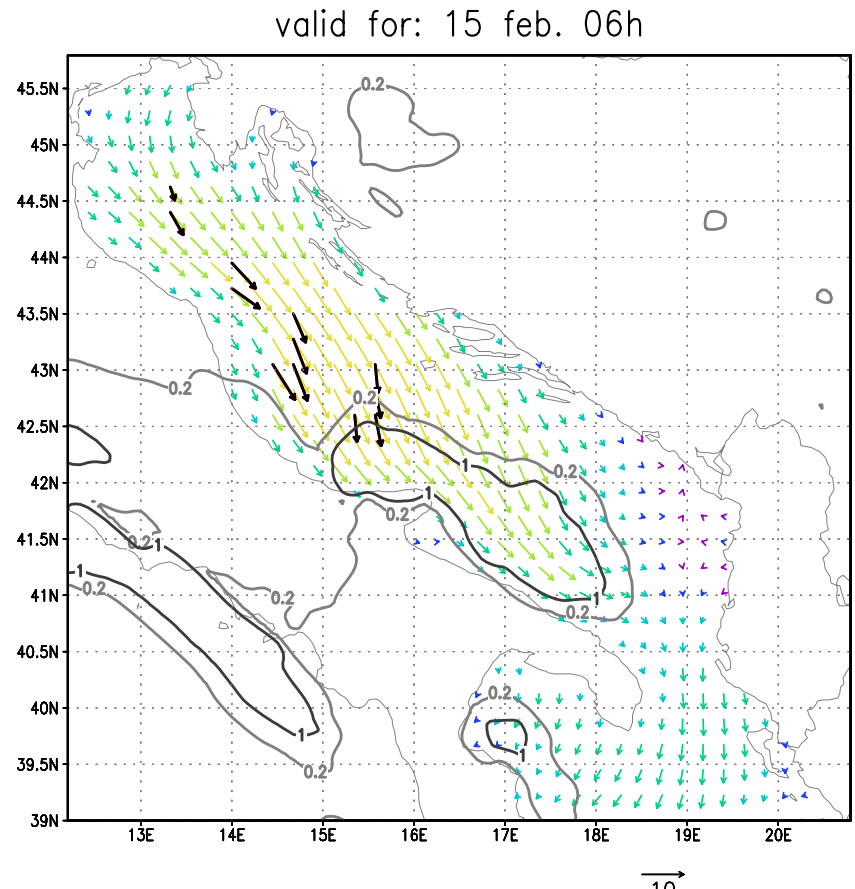

$\overrightarrow{10}$
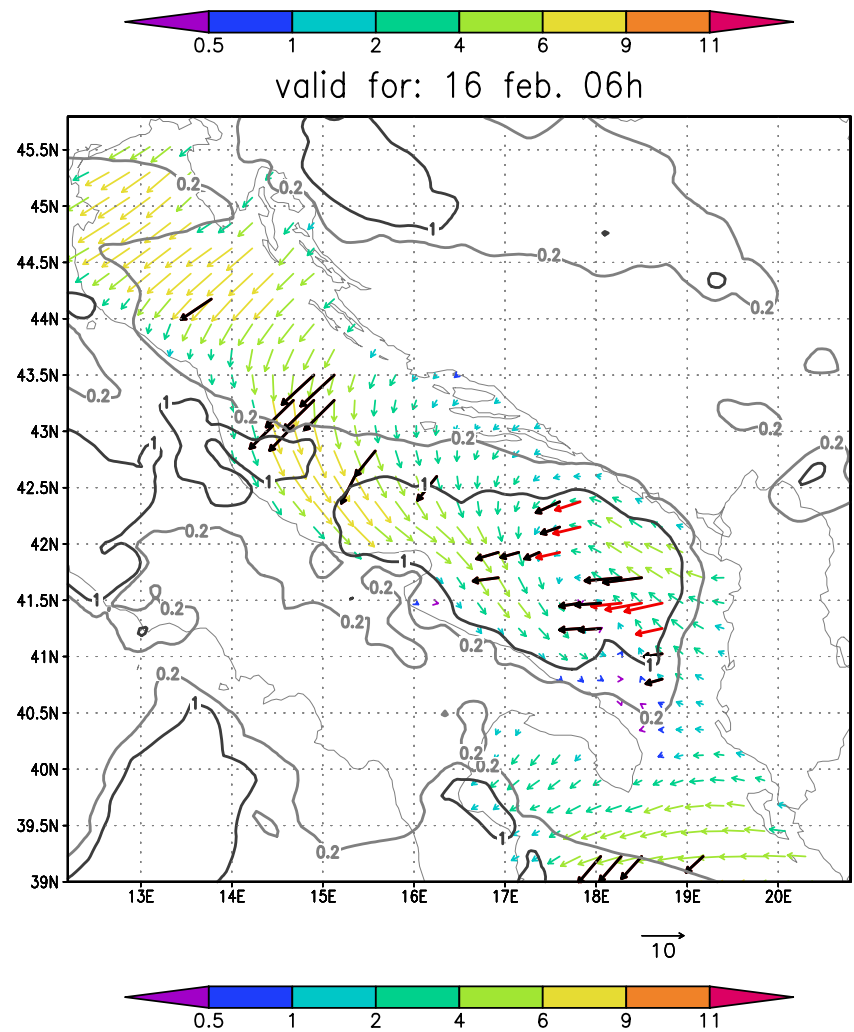

Fig. 12. Same as Fig. 11 except for 15-16 February.

clouds and rain. Due to the relatively coarse resolution of the wind measurements, there appear to be more observational points than in reality. They are visible, as they tend to form groups of vectors with the same speed and direction.
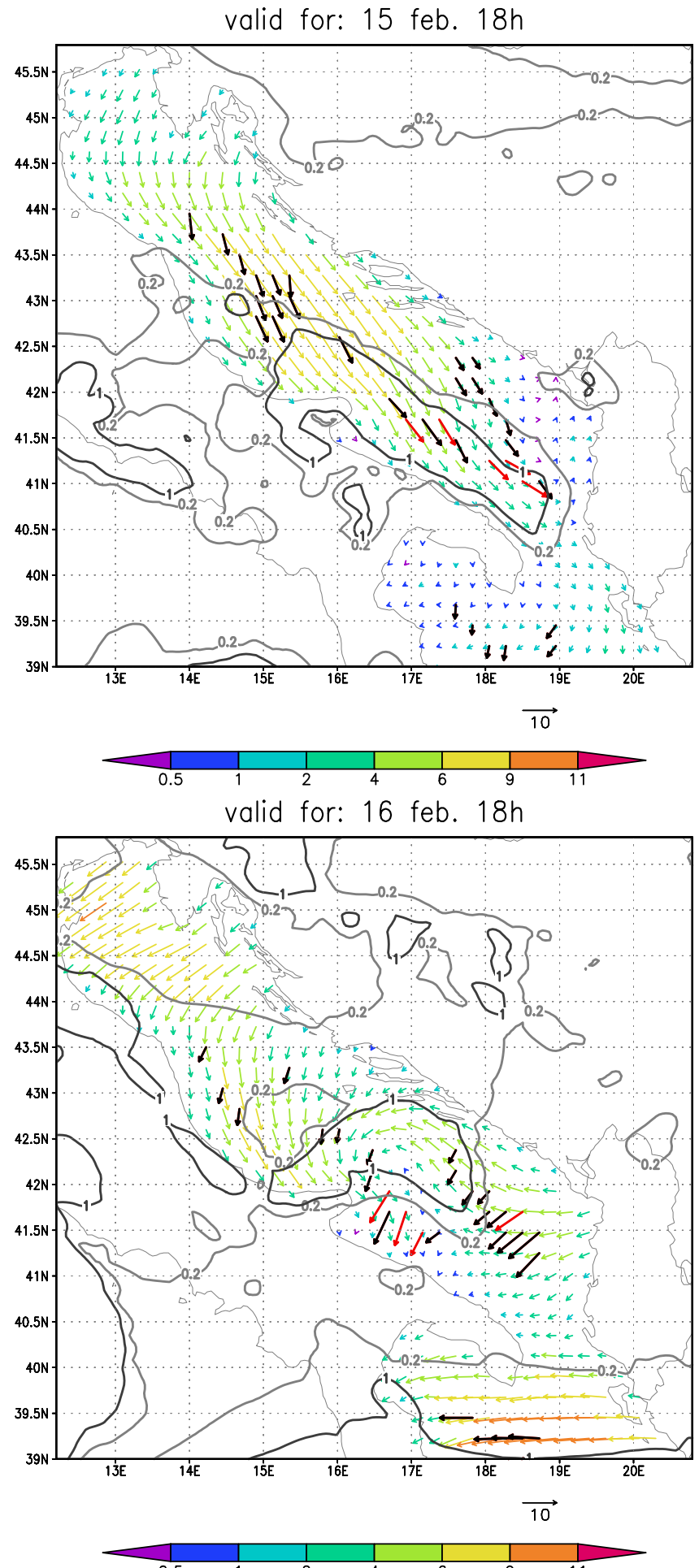

0.5

Looking figure-by-figure, the quality of the wind forecast varies over time. The forecast with the largest error in the wind speed is the one for 16 February. However, more detailed examination shows that for that particular day a large 

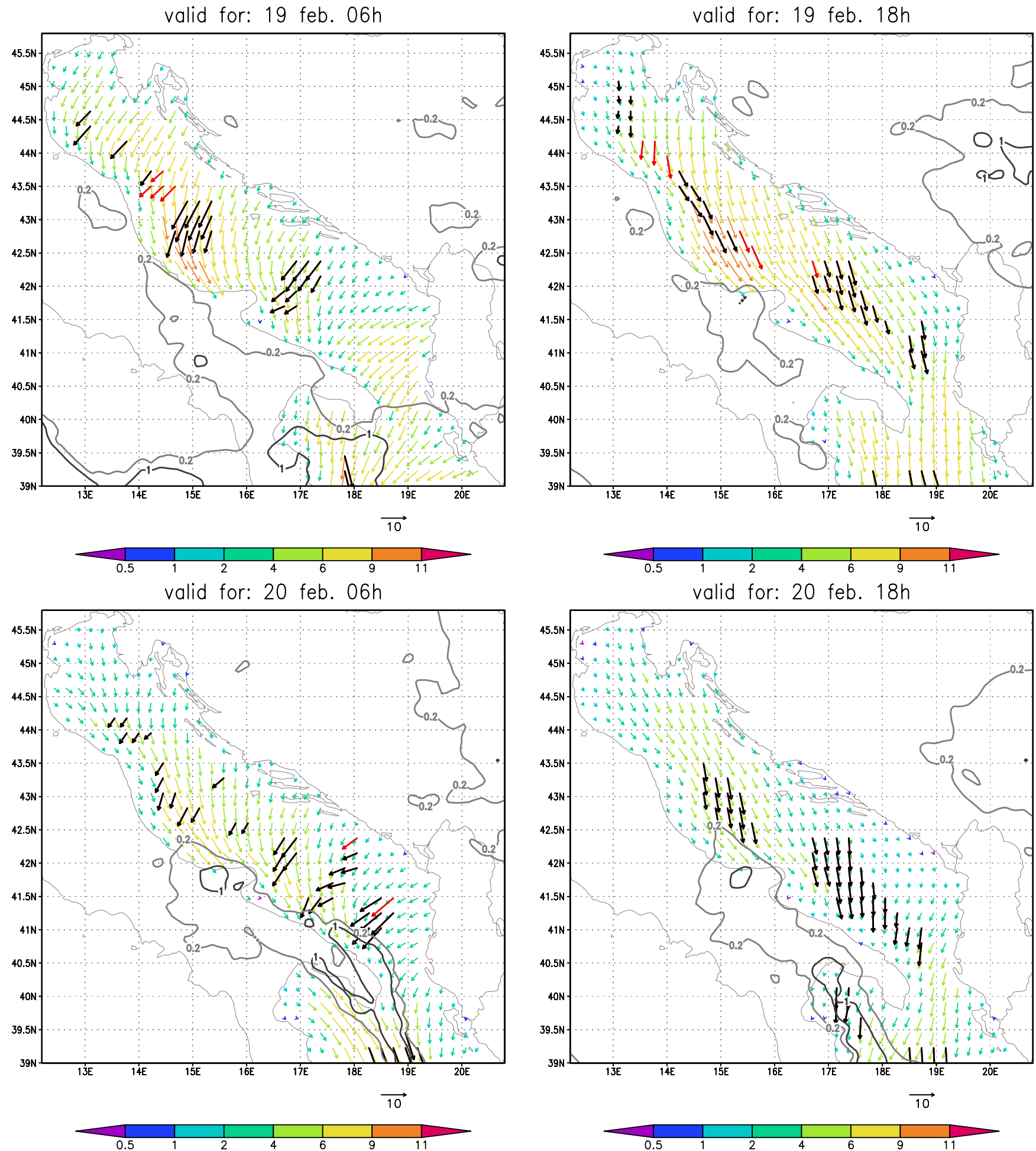

Fig. 13. Same as for Fig. 11, but for 19-20 February.

area was covered by clouds/rain. At all other times, when the domain was cloud-free, we obtain quite good agreement for both weak winds at the end of the forecast period, when winds turn from the northerly to the southerly direction (bora to sirocco); and strong winds, such as on 24 February is a good example. Another feature of the wind field can be analyzed from these figures. Since we had data from two satellite passes for each day, we can examine the diurnal variation 

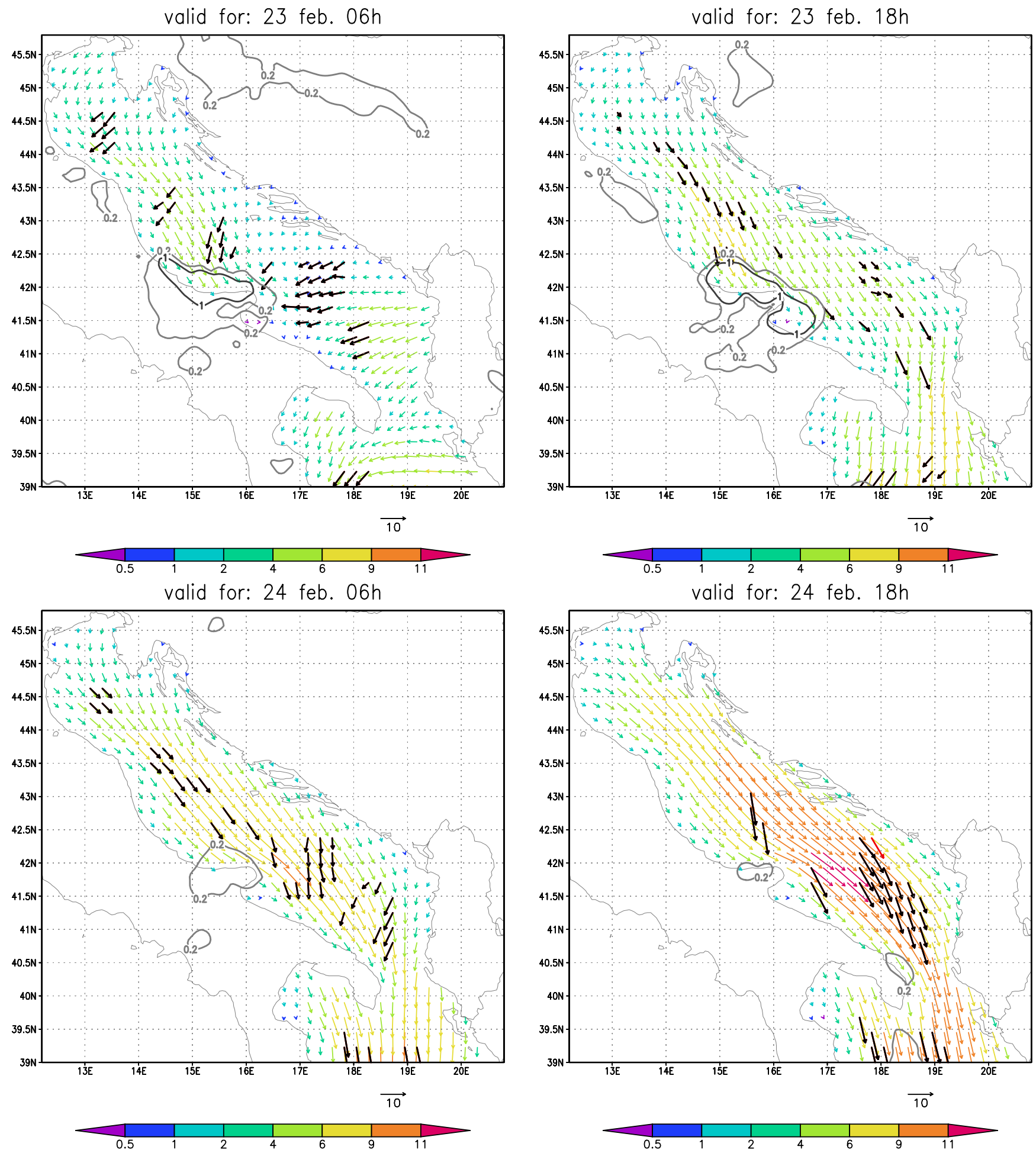

Fig. 14. Same as Fig. 11, except for 23-24 February.

in wind direction and speed. Visual inspection reveals that these variations were quite correctly represented.

We now describe the wind field during the integration period. At the beginning, for 00:00 h, wind blows parallel to the coast from the northwest. Twelve hours later we see the first signs of Bora formation, which intensifies through the morning of the 16 February at 00:00 h. Twelve hours later, it becomes weaker still with the prevailing direction 

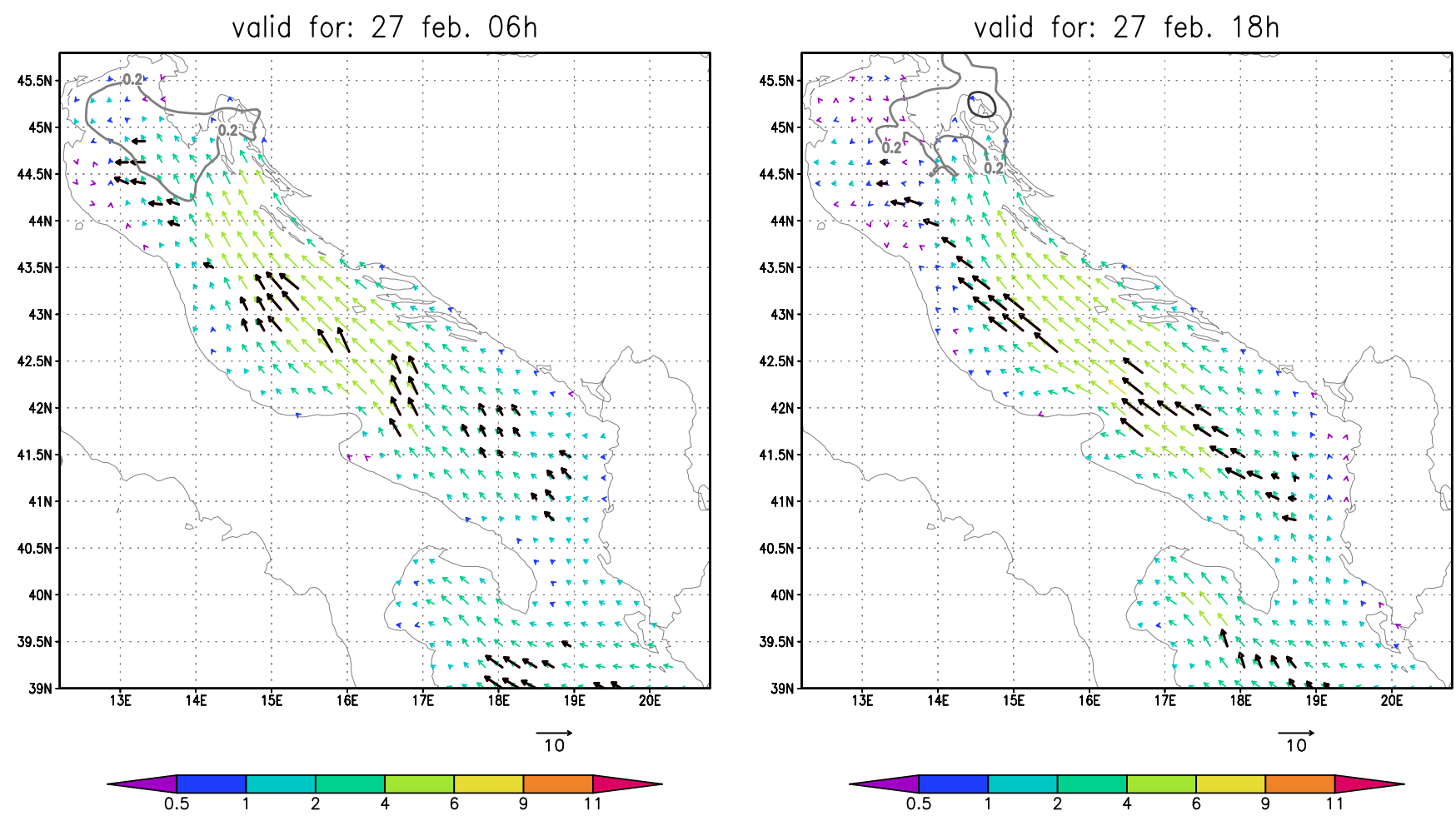

Fig. 15. Same as Fig. 11, but for 27 February.

being from the coast towards the sea across the entire width of the Adriatic Sea. These conditions continue for the next $12 \mathrm{~h}$, with the signal arriving nearly to the Italian coast of the Adriatic. In the next term it weirs parallel to the coast but returns to the normal Bora direction $12 \mathrm{~h}$ later. These small changes in direction are observed until 27 February, when the wind switches over a 12-h period from clear Bora to Siroko. It subsequently blows along the Adriatic Sea axis from the southeast. Though it is variable in intensity, it is present thought the Adriatic basin. At 06:00 h, the wind is weaker in the South than in the central Adriatic. The next time interval, 18:00 h, is characterized by a more homogeneous wind field in the southern and central part, and by extremely weak winds in the northern part of the Adriatic.

Finally, we present verifications only for the Northern Adriatic, for the period of 15-20 February 2006, a subset of the entire study period that is characterized by the presence of a strong bora wind. Histograms of the observed and simulated values are shown as a time sequence in Fig. 16. The upper panel shows wind speed, while the lower panel displays wind direction. Here, agreement between observed and forecasted wind is even better than for the whole Adriatic, albeit with several exceptions. The mean wind speed BIAS for that period is $-0.8 \mathrm{~m} / \mathrm{s}$, which means that for most of the time, the model predicted weaker winds than were observed. As before, there are several instances where the verification area was reduced due to the existence of rain or clouds based on the forecast, such as on 16 February. On the other hand, for 19 February, the forecast predicted a "clear" sky at both 06:00 $\mathrm{h}$ and 18:00 $\mathrm{h}$, so the verification area was larger, and it showed excellent agreement between the observations and the forecast.

\section{Conclusions}

We demonstrate here that it is possible to calculate quite accurate SST and surface winds using EBU-POM, a coupled ocean-atmosphere model with sufficiently high resolution in both components. We were able to verify this using remote sensing, which allowed us to calculate area averages of these quantities and to calculate statistical scores such as RMSE and BIAS. Both were scores were excellent when sufficient data were available; problems arose, however, when there was clouds or precipitation in the verification area. Even though we analysed seven-day forecasts, and in one case a 17-day hindcast, the forecast quality did not degrade in most cases. In fact, it even improved during the integrations in several cases. BIAS was between $1.2^{\circ}$ and $-1.1^{\circ}$, and it was negative in most cases, while RMSE scores were between $1.1^{\circ}$ and $1.2^{\circ}$. In several forecasts, the initially large error decreased substantially as integration progressed. Using night and day satellite passes, we were able to verify that the diurnal signal of both SST and surface wind was correctly predicted. BIAS for the winds was $-0.8 \mathrm{~m} / \mathrm{s}$. The model 

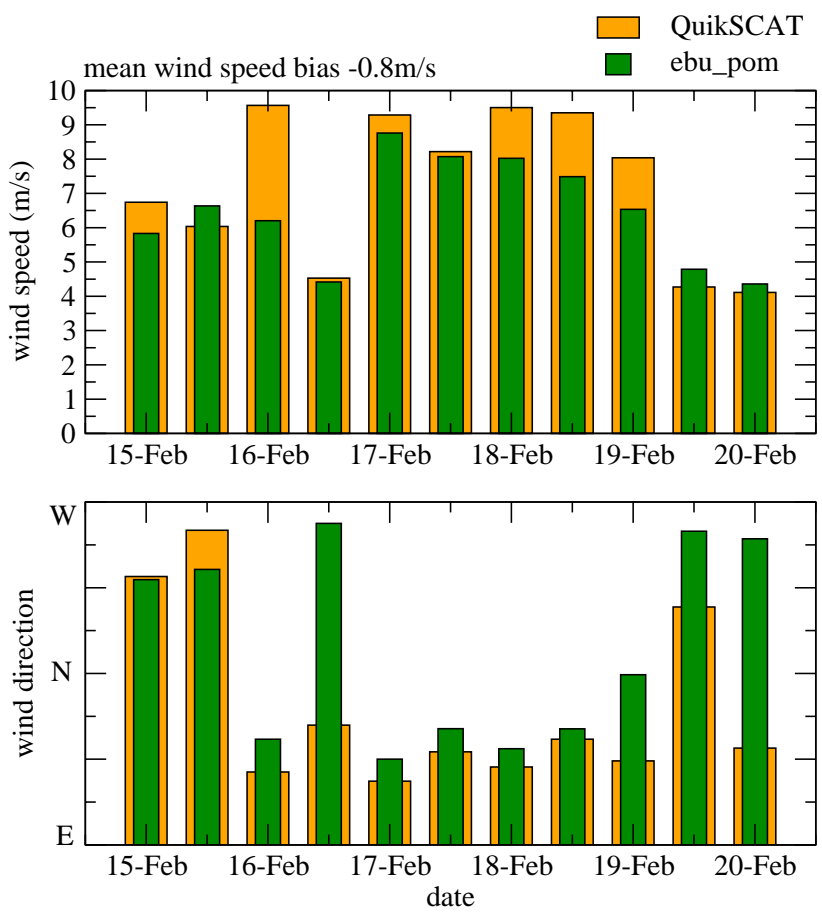

Fig. 16. Verification of wind speed (upper panel) and wind direction (lower panel) with QuickSCAT data. QuickSCAT data are shown in orange, and the model predictions are shown in green. The period of verification was 15-20 February. Mean BIAS for wind speed was approximately $-0.8 \mathrm{~m} / \mathrm{s}$.

forecasts were relatively insensitive to whether initial fields were derived from ECMWF or NCEP. The notable exception was when predicted SST differed by almost one degree from observed values due to errors in the ECMWF forecasts.

\section{Appendix A}

\section{Verification scores}

The most common scores for forecast verification are BIAS and root mean square error (RMSE). BIAS score is defined as the difference between the forecast value $F$ and the observed value $Y$. For the point and moment in which we have observation and forecasts for a given variable, we obtain:

$$
\mathrm{BIAS}=F-Y
$$

For an area that is covered by $N$ observations at a defined moment, we can calculate the area-averaged BIAS as:

BIAS $=\frac{1}{N} \sum_{i=1}^{N} F_{i}-Y_{i}$

Bias does not measure the magnitude of the errors and does not measure the correspondence between forecasts and observations. In other words, it is possible to obtain a perfect score for a bad forecast if there are compensating errors. For a perfect forecast, the BIAS value is zero.

For root mean square error, the variable in the definition of the mean is $(Y-F)^{2}$. The area-averaged RMSE, over an area with $N$ observations for a specific moment, is defined as:

$\mathrm{RMSE}=\sqrt{\frac{1}{N} \sum_{i=1}^{N}\left(F_{i}-Y_{i}\right)^{2}}$

RMSE is a measure of the accuracy of the forecast compared to observations. The score is always greater than or equal to zero. If the forecast is perfect, RMSE is zero. The RMSE does not indicate the direction of the deviations. The RMSE is more sensitive to large errors than to small errors, which may be valuable if large errors are especially undesirable, but it may also encourage conservative forecasting.

Acknowledgements. The majority of this research was sponsored through UNESCO's ADRICOSM-EXT project. Additional support came from the Ministry of Science, Technologies, and Development of the Republic of Serbia (grant no. 1197). We would also like to thank Mirjam Vujadinovic for technical assistance during preparation of earlier versions of this paper.

Topical Editor S. Gulev thanks two anonymous referees for their help in evaluating this paper.

\section{References}

Aikman, F., Mellor, G. L., Ezer, T., Sheinin, D., Chen, P., Breaker, L., Bosley, K., and Rao, D. B.: Towards an operational nowcast/forecast system for the U.S. east coast, in: Modern Approaches to Data Assimilation in Ocean Modeling, Elsevier Oceanography Series, 61, edited by: Malanotte-Rizzoli, P., 347376, 1996.

Arakawa, A. and Lamb, V.: Computational design of the basic dynamical processes of the UCLA general circulation model, Methods in Computational Physics, 17, 174-265, Academic Press, 1977.

Artegiani, A., Bregant, D., Paschini, E., Pinardi, N., Raicich, N., and Russo, A.: The Adriatic Sea General Circulation. Part I: airsea interactions and water mass structure, J. Phys. Oceanogr., 27, 1492-1514, 1997.

Beg Paklar, G., Isakov, V., Koracin, D., Kourafalou, V., and Orlic, M.: A case study of bora-driven flow and density changes on the Adriatic shelf (January 1987), Cont. Shelf Res., 21, 1751-1783, 2001.

Beg Paklar, G., Bajic, A., Dadic, V., Grbec, B., and Orlic, M.: Borainduced currents corresponding to different synoptic conditions above the Adriatic, Ann. Geophys., 23, 1083-1091, 2005, http://www.ann-geophys.net/23/1083/2005/.

Betts, A. K.: A new convective adjustment scheme. Part I: Observational and theoretical basis, Q. J. Roy. Meteor. Soc., 112, 677691, 1986.

Betts, A. K. and Miller, M. J.: A new convective adjustment scheme. Part II: Single column test using GATE wave, BOMEX, ATEX and artic air-mass data sets, Q. J. Roy. Meteorol. Soc., 112, 693-709, 1986. 
Blumberg, A. and Mellor, G.: Description of a three-dimensional coastal ocean circulation model., in: Three-Dimensional Coastal Ocean Models, 4, edited by: Heaps, N., 208, American Geophysical Union, 1986.

Djurdjevic, V. and Rajkovic, B.: Air-sea interaction in Mediterranean area, Spring Colloquium on the Physics of Weather and Climate "Regional weather prediction modeling and predictability", ICTP, Trieste, Italy, 2002.

D'ortenzio, F., Marullo, S., and Santoleri, R.: Validation of AVHRR Pathfinder SST's over the Mediterranean Sea, Geophys. Res. Lett., 2, 241-244, 2000.

Dorman, C. E., Carniel, S., Cavaleri, L., Sclavo, M., Chiggiato, J., Doyle, J., Haack, T., Pullen, J., Grbec, B., Vilibic, I., Janekovic, I., Lee, C. M., Malacic, V., Orlic, M., Paschini, E., Russo, A., and Signell, R. P.: February 2003 marine atmospheric conditions and the bora over the northern Adriatic, J. Geophys. Res., 111(C3), C03S03, doi:10.1029/2005JC003134, 2006.

Enger, L. and Grisogono, B.: The response of bora-type flow to sea surface temperature, Q. J. R. Meteorol. Soc., 124, 1227-1244, 1998.

Fels, S. B. and Schwarzkopf, M. D.: The simplified exchange approximation: A new method for radiative transfer calculations, J. Atmos. Sci., 32, 1475-1488, 1975.

Freilich, M. H. and Dunbar, R. S.: The accuracy of the NSCAT-1 vector winds: comparisons with NDBC buoys. J. Geophys. Res., 104, 11 231-11 246, 1999.

Janjic, Z. I.: Forward-backward scheme modified to prevent twogrid-interval noise and its application in sigma coordinate models, Contrib. Atmos. Phys., 52, 69-84, 1979.

Janjic, Z. I.: Non-linear advection schemes and energy cascade on semi staggered grids, Mon. Weather Rev., 112, 1234-1245, 1984.

Janjic, Z. I.: Physical package for step-mountain, Eta coordinate model, Mon. Weather Rev., 118, 1429-1443, 1990.

Janjic, Z. I.: The surface layer parameterization in NCEP Eta model, WMO, Geneva, CAS/C WGNE, 4.16-4.17, 1996.

Jeffries, M. and Lee, C. M.: A climatology of the Northern Adriatic Sea's response to bora and river forcing, J. Geophys. Res., 112, C03S02, doi:10.1029/2006JC003664, 2007.

Lee, C. M., Askari, F., Book, J., Carniel, S., Cushman-Roisin, B., Dorman, C., Doyle, J., Flament, P., Harris, C. K., Jones, B. H., Kuzmic, M., Martin, P., Ogston, A., and Orlic, M., Perkins, H., Poulain, P., Pullen, J., Russo, A., Sherwood, C., Signell, R. P., and Thaler, D.: Transport Pathways of the Adriatic: MultiDisciplinary Perspectives on a Wintertime Bora Wind Event, EOS Transactions, American Geophysical Union, 86(16), 157168,2005

Kilpatrick, K. A., Podestr, G. P., and Evans, R.: Overview of the NOAA/NASA advanced very high resolution radiometer Pathfinder algorithm for sea surface temperature and associated match up atabase, J. Geophys. Res., 106, 9179-9197, 2001.

Mahrt, L., Pan, H.-L., Ruscher, P., Chu, C.-T., and Mitchell, K.: Boundary layer parameterization for a global spectral model, Tech. Rept. No. AFGL-TR-87-0246, 1-210, Air Force Geophysics Laboratory, Ha nscom, AFB, Massachusetts 01731, 1988.

Mantziafou, A. and Lascaratos, A.: An eddy resolving numerical study of the general circulation and deep-water formation in the Adriatic Sea, Deep Sea Res. I, 51(7), 251-292, 2004.

Manzella, G., Scoccimarro, E., Pinardi, N., and Tonani, M.: Im- proved near real time data management procedures for the mediterranean ocean forecasting system-voluntary observing ship program, Ann. Geophys., 21, 49-62, 2003, http://www.ann-geophys.net/21/49/2003/.

Mellor, G. and Yamada, T.: A hierarchy of turbulence closure models for the planetary boundary layer, J. Atmos. Sci., 31, 17911806, 1974.

Mellor, G. L. and Yamada, T.: Development of a turbulence closure model for geophysical fluid problems, Rev. Geophys. Space Phys., 20(4), 851-875, 1982.

Mellor, G. L. (Ed.): Users guide for a three-dimensional primitive equation numerical ocean model, Program in Atmospheric and Oceanic Sciences, Princeton University, Princeton, NJ 085440710, 2002.

Mesinger, F.: An economical explicit scheme which inherently prevents the false two-grid-interval wave in the forecast fields, Proc. Symp. "Difference and Spectral Methods for Atmosphere and Ocean Dynamics Problems", Academy of Sciences, Novosibirsk, 17-22 September 1973, Part II, 18-34, 1974.

Mesinger, F., Janjic, Z. I., Nickovic, S., Gavrilov, D., and Daven, D.: The step mountain coordinate: model description and performance for cases of alpine lee cyclogenesis and for a case of an Appalachian redevelopment, Mon. Weather Rev., 116, 1493 1518, 1988.

Oddo, P., Pinardi, N., and Zavatarelli, M.: A numerical study of the interannual variability of the Adriatic Sea (2000-2002), Sci. Tot. Environ., 353, 39-56, 2005.

Orlic, M., Kuzmic, M., and Pasaric, Z.: Response of the Adriatic Sea to the bora and sirocco forcing, Cont. Shelf Res., 14(1), 91116, 1994.

Orlic, M., Dadic, V., Grbec, B., Leder, N., Marki, A., Matic, F., Mihanovic, H., Beg Paklar, G., Pasaric, M., Pasaric, Z., and Vilibic, I.: Wintertime buoyancy forcing, changing seawater properties, and two different circulation systems produced in the Adriatic, $\mathrm{J}$. Geophys. Res., 111, C03S07, doi:10.1029/2005JC003271, 2006.

Pasaric, Z., Orlic, M., and Lee, C. M.: Aliasing due to sampling of the Adriatic temperature, salinity and density in space, Estuarine, Coastal Shelf Sci., 69, 636-642, 2006.

Peters, H., Lee, C. M., Orlic, M., and Dorman, C. E. Turbulence in the Wintertime Northern Adriatic Sea Under Strong Atmospheric Forcing, J. Geophys. Res., 112, C03S09, doi:10.1029/2006JC003634, 2007.

Pinardi, N., Allen, I., Demirov, E., De Mey, P., Korres, G., Lascaratos, A., Le Traon, P-Y., Maillard, C., Manzella, G., and Tziavos, C.: The Mediterranean Ocean Forecasting System: First phase of implementation (1998-2001), Ann. Geophys., 21, 320,2003 http://www.ann-geophys.net/21/3/2003/.

Pullen, J., Doyle, J. D., Hodur, R., Ogston, A., Book, J. W., Perkins, H., and Signell, R.: Coupled ocean-atmosphere nested modeling of the Adriatic Sea during winter and spring 2001, J. Geophys. Res., 108, 3320, doi:10.1029/2003JC001780, 2003.

Pullen, J., Doyle, J. D., Haack, T., Dorman, C., Signell, R. P., and Lee, C. M.: Bora event variability and the role of air-sea feedback, J. Geophys. Res., 112, C03S18, doi:10.1029/2006JC003726, 2007.

Sciarra, R., Bohm, E., D'acunzo, E., and Santoleri, R.: The large scale observing system component of ADRICOSM: the satellite system., Acta Adriat., 47 (Suppl.), 51-64, 2006. 
Signell, R. P., Carniel, S., Cavaleri, L., Chiggiato, J., Doyle, J. D., Pullen, J., and Sclavo, M.: Assessment of wind quality for oceanographic modelling in semi-enclosed basins, J. Mar. Syst., 50, 217-233, 2005.

Winninghoff, F. J.: On the adjustment toward a geostrophic balance in a simple primitive equation model with application to the problems of initialization and objective analysis, Ph.D. thesis, Department of Meteorology, University of California, Los Angeles, 161, 1968.

Walton, C. C., Pichel, W. G., Sapper, J. F., and May, D. A.: The development and operational application of non-linear algorithms for the measurements of sea surface temperature with the NOAA polar-orbiting environmental satellites, J. Geophys. Res., 103(12), 27 999-28 012, 1998.
Zavatarelli, M., Pinardi, N., Kourafalou, V. H., and Maggiore, A.: Diagnostic and prognostic model studies of the Adriatic Sea general circulation. Seasonal variability, J. Geophys. Res., 107(C1), 4-1-4-20., 2002.

Zavatarelli, M. and Pinardi, N.: The Adriatic sea modeling system: A nested approach, Ann. Geophys., 21, 345-364, 2003, http://www.ann-geophys.net/21/345/2003/. 